\title{
Resource-constrained project scheduling problem: review of past and recent developments
}

\author{
Farhad Habibi*, Farnaz Barzinpour and Seyed Jafar Sadjadi
}

Department of Industrial Engineering, Iran University of Science and Technology, Tehran, Iran

\begin{tabular}{l}
\hline C H R O N I C L E \\
\hline Article history: \\
Received: July 5, 2017 \\
Received in revised format: Octo- \\
ber 10, 2017 \\
Accepted: January 4, 2018 \\
Available online: \\
January 4, 2018 \\
\hline Keywords: \\
Project scheduling \\
Optimization \\
Resource constraint \\
Review \\
Classification
\end{tabular}

A B S T R A C T

\begin{abstract}
The project scheduling problem is both practically and theoretically of paramount importance. From the practical perspective, improvement of project scheduling as a critical part of project management process can lead to successful project completion and significantly decrease of the relevant costs. From the theoretical perspective, project scheduling is regarded as one of the interesting optimization issues, which has attracted the attention of many researchers in the area of operations research. Therefore, the project scheduling issue has been significantly evaluated over time and has been developed from various aspects. In this research, the topics related to Resource-Constrained Project Scheduling Problem (RCPSP) are reviewed, recent developments in this field are evaluated, and the results are presented for future studies. In this regard, first, the standard problem of RCPSP is expressed and related developments are presented from four aspects of resources, characteristics of activities, type of objective functions, and availability level of information. Following that, details about 216 articles conducted on RCPSP during 1980-2017 are expressed. At the end, in line with the statistics obtained from the evaluation of previous articles, suggestions are made for the future studies in order to help the development of new issues in this area.
\end{abstract}

\section{Introduction}

In developing countries, implementation of projects plays a fundamental and effective role in the national development and improvement of economy. In these countries, projects are regarded as the wheels of the vehicle of growth and development in economic dimensions. In general, projects carried out at the national level are often large projects with great budgets. Therefore, optimal and accurate management of these projects leads to successful implementation of the project, increased revenues, and decreased costs and lost profits. One of the important duties of project management is scheduling, which has been turned into a difficult task due to resource constraints along with precedence relationships. As a result, the problem of project scheduling is considered by researchers as one of the most commonly used and fundamental issues, and development of this standard issue has been addressed in various aspects. Therefore, despite the extended assessment of project scheduling, further studies must

* Corresponding author.

E-mail address: farhadhabibi1993@gmail.com (F. Habibi) 
be carried out to review the previously conducted researches to provide the condition for future studies through presenting a categorization of this type of problem. In the present research, project scheduling problem and its categorization are evaluated from various aspects.

\section{Resource-Constrained Project Scheduling Problem (RCPSP)}

The project scheduling problem is identified as determining the time required to implement the activities of a project to achieve a certain objective. In primary researches on project scheduling, it was assumed that the activities of a project are described only by the implementation of time duration. Therefore, methods, such as critical path method (CPM) and program evaluation and review technique (PERT), are proposed by considering the precedence relationships between the activities of a project. However, since the considering of precedence relationships to be independent seems to be an unreasonable assumption, it is aimed to apply some constraints and evaluate their effects. One of the major limitations of project scheduling is resource constraints, which is considered as a standard problem for project scheduling and is recognized with the title of Resource-Constrained Project Scheduling Problem (RCPSP). In this problem, a project with $J$ activities labeled $j=1, \ldots, J$ is considered. In addition, the processing time (i.e., duration) of an activity $j$ is represented by $d_{j}$, which once started, the activity must be completed without interruption. In general, there are precedence relationships between the activities with regards to technological requirements. These relationships are shown by sets of immediate predecessors $P_{j}$, indicating that an activity $j$ cannot be started before the completion of each of its predecessors $\left(i \in P_{j}\right)$. In addition, these relationships can be represented in the form of a network. A certain amount of resources is required for each activity to be performed. Owing to a full capacity available in every period, the resources are recognized as renewable. In total, we have $K$ types of renewable resources labeled $k=1, \ldots, K$. For each resource $k$, it is assumed that $R_{k}$ constant amount of resource is available before the start of each period. In order to perform activity $j$ in each period, where the processing is carried out, $r_{j k}$ unit of resource $k$ is required. Two additional activities $j=0$ and $j=J+1$, which represent the start and end of the project, respectively, are also regarded. Since both are dummy activities, their processing time and resource consumption are zero. All information of the problem is assumed to be deterministic and definite, and the parameters are considered non-negative and integer valued. In this problem, the aim is to find the start time $\left(S_{j}\right)$ for the activities $j=0,1, \ldots, J+1$, in a way that the completion time of the project is minimized (Hartmann \& Briskorn, 2010).

The basic form of resource-constrained project scheduling problem is as mentioned above. However, since the situation is completely different in practice, changes have been made to the basic assumptions by the researchers over time. In addition, Blazewicz et al. (1983) have shown that the RCPSP problem belongs to the class of the strongly NP-hard problems. As a result, various solutions are used according to the changes in the basic assumptions. In the following, changes which have occurred in the general form of the base problem over time are evaluated and categorized from the perspective of four main dimensions and their subcategories, according to Fig. 1.

\section{Classification of RCPSPs}

\subsection{Resource constraint}

As mentioned earlier, each activity in the project requires resources to be implemented. The need to resources, only in the form of renewable resources and assuming that they have a full capacity in each period and a fixed amount of the resource is occupied during the implementation of the activity, has been assessed in the basic RCPSP. Since the type of the consumption resource(s) of an activity depends on the nature of that activity, various resources have been evaluated, among which renewable, nonrenewable and doubly constrained resources have attracted the most attention from the researchers. 


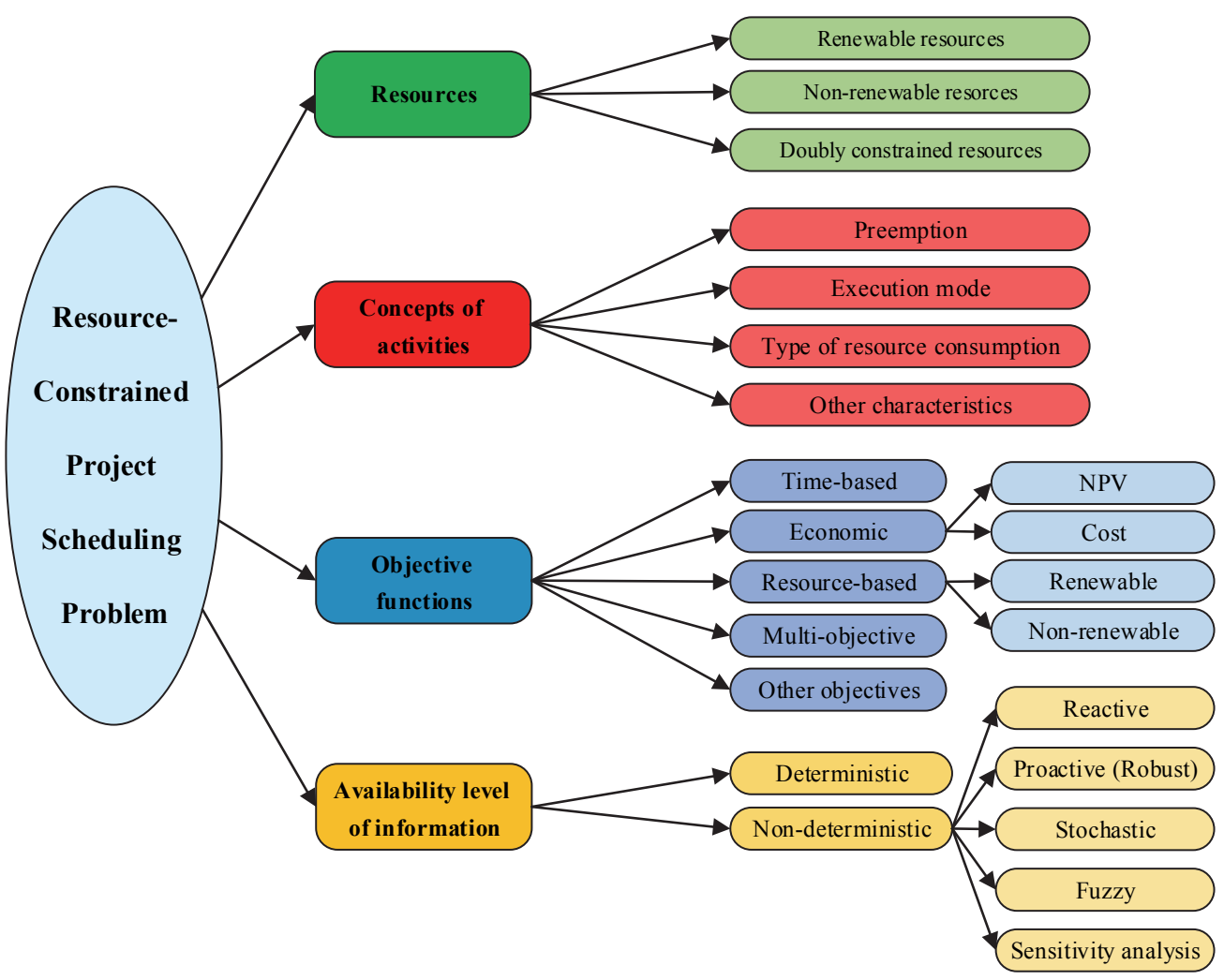

Fig. 1. Classification of resource-constrained project scheduling problems

\subsubsection{Renewable resources}

Most of the articles on scheduling problems have regarded renewable resources to perform their activities. It means that resource constraints have been periodic and when the activities are initiated, a specific amount of this type of resources is exploited and returned at the end of the process. In the basic RCPSP, consumption of this type of resources along with precedence constraints of activities are evaluated. In addition, it is assumed that the amount of resource consumption and available capacity of each of them are in the form of integers. In this regard, human resources and machinery are considered to be this type of resources (Carlier \& Moukrim, 2015).

In some studies, renewable resources are divided into two categories:

- Extremely expensive resources (type A), which must be provided for a short duration of the project. This type of resources must be prepared and obtained from the outside during the scheduled time.

- Renewable resources (type B), which are completely available for organizations (GolenkoGinzburg et al., 2006).

\subsubsection{Non-renewable resources}

Another resource used by activities, which is categorized by Słowiński (1980), is known as non-renewable resources. While the renewable resources are periodically renewed and their limited amount can vary from one period to another, the non-renewable resources are limited within the project horizons. In other words, this type of resources has limited access to total consumption over the entire period of the project and not in each periodic course. The required raw material is one of the most significant examples of non-renewable resources since they are available for a project at a specific and determined 
amount (Kyriakidis et al., 2012). Moreover, the total cost of the project is regarded as non-renewable resource (Wang et al., 1993).

\subsubsection{Doubly constrained resources}

Another categorization of resources stated in Słowiński (1980) is doubly constrained resources. This category of resources has the properties of both renewable and non-renewable resources. In other words, the access to these resources is limited both in each period and the total duration of the project (Kyriakidis et al., 2012). Other examples of this type of resources are money and energy. Meanwhile, they are regarded as doubly constrained resources due to constraints caused by accessibility and use during the project implementation (Kogan \& Khmelnitsky, 1998). Given the fact that a doubly constrained resource can be regarded in a problem by a renewable and a non-renewable resource, this category of resources requires no separate consideration (Hartmann \& Briskorn, 2010).

\subsection{Characteristics of activities}

With regards to the development of RCPSP in all dimensions over time, developments have been made in the concepts and assumptions related to the activities of the project. Without a doubt, these assumptions are not limited to theoretical research and are significantly applicable in the real world. In this section, some of these concepts are described:

\subsubsection{Preemptive scheduling}

One of the main assumptions related to the basic RCPSP is that the activities of the project cannot be interrupted or discontinued. In other words, an activity must continue to the end without any interruptions. However, in practice, some activities must be stopped during the processing, which can be due to destructions or disabilities of resources, equipment repair, and etc (Chen \& Zhang, 2016). The Preemption Resource-Constrained Project Scheduling Problem (PRCPSP) was first introduced by Kaplan (1988). Given the fact that in PRCPSP problem, activities are allowed to be stopped at any time of the process and be continued at another time without any additional costs, this type of problem can better simulate the actual scheduling process. Similar to PRCPSP problems, Van Peteghem and Vanhoucke (2010) assumed that preemption of activities was allowed at any time of performing the activities. In addition, it was observed in Moukrim et al. (2015) that no fee was regarded as penalty for preemption of activities. Shadrokh (2010), Afshar-Nadjafi and Majlesi (2014), Afshar-Nadjafi (2014b), Ballestín et al. (2009), and Demeulemeester and Herroelen (1996) allowed the interruption of activities in discrete points of time. In other words, the activity can be stopped at each integer time unit of the processing period. In their scheduling problem, Chen and Zhang (2016) assumed that an activity can be interrupted one or more times during the processing period; However, Zhu et al. (2011) assumed that an activity can be interrupted at most $m$ times. In addition, Li et al. (2011) and Shou et al. (2015) allowed the activities to be interrupted with a maximum of one time. In Fallah et al. (2010), it was assumed that access to resources was associated with uncertainty and activities could be interrupted in case of destructed resources. Zhang et al. (2006) evaluated Preemptive Scheduling under Break and Resource-Constraints (PSBRC), where the activities were stopped during the break and the stopped activity could not be immediately started in the next period due to resource constraints, which must be reallocated during the break. Buddhakulsomsiri and Kim (2006) and Buddhakulsomsiri and Kim (2007) used a similar approach by allowing the activities to be interrupted due to the rest of resources. Tavana et al. (2014) regarded preemption project scheduling problem with three specific features. First, there was a limitation as the minimum duration of processing activity before the first interruption. In addition, a high limit for the number of preemptions in one activity and a maximum duration as limitation for duration between the interruption and restart of the activity were defined. Vanhoucke and Debels (2008) regarded another type of preemption of activities in the project scheduling problem, 
called fast tracking option. Their assumption was that the parts of an activity that were separated due to interruption would require no processing in sequence and could be performed in a parallel manner.

\subsubsection{Activities execution mode}

In the basic RCPSP, it is assumed that the activities are performed by one method and within a determined processing time and with specific (renewable) resource consumption. Elmaghraby (1977) was proposed as a start for the assumption of multi-mode activities, in which several techniques or alternatives exist to implement the activities, each having its own specific processing duration and resource consumption amount (Hartmann \& Briskorn, 2010). Assumptions of multi-mode RCPSP are, as follows: an activity $j$ must be performed by one of the methods determined by $1, \ldots, M_{j}$, where $M_{j}$ indicates the number of implementation methods of activity $j$. Moreover, when performing of an activity is initiated by one of the possible methods, the activity must be processed in the same way until completion. In other words, no interruption is allowed during the activity. Duration of activity $j$, which is processed by method $m$, is shown by $d_{j m}$, and the demand for activity $j$, which is processed by method $m$, is mentioned by $r_{j m k}$ for resource $k$, which demonstrates that the implementation duration of activity $j$ and the amount of consumption of resource $k$ by activity $j$ will be different for each processing method. In multi-mode RCPSP, non-renewable resources are often considered along with renewable resources, so that the start time of the activities $\left(S_{j}\right)$ along with the method of activities $\left(m_{j}\right)$ are determined in a way that the minimum duration required for the completion of the project (which is the most common type of objective in the literature) is obtained. Generally, multi-mode RCPSP problem is recognized as Multi-mode Resource-Constrained Project Scheduling Problem (MRCPSP), which is more general, compared to RCPSP.

In their scheduling problem, Santos and Tereso (2011) involved multi-skilled human resources and assumed that the activities can be performed by various methods, each using their own specific skill level, which resulted in different costs and processing durations. Since the main scheduling timetable might be infeasible in some cases due to disturbances in resources and the duration of activities, modifications must be made in the scheduling timetable. Therefore, Deblaere et al. (2011) presented a number of methods for scheduling, which repaired the disruption in main scheduling timetable that included RCPSP with multi-mode activities. Beşikci et al. (2015) introduced a multi-mode scheduling problem in the multi-project environment, where there was a specific deadline for each project. Each activity had selective methods for consumption of resources and a policy was regarded for allocation of resources to prevent the sharing of resources among the projects during the planning horizon along with a budget level that must be distributed between various resources to determine the total capacity of the resources. Delgoshaei et al. (2016) presented a new method to modify the excessive allocation of resources for RCPSP, in which it was assumed that activities could be interrupted. Despite the possibility of performing the activity in several methods, if one method is initiated to perform the activity, it must be the same method used during the implementation of activity.

\subsubsection{Resource request varying with time}

In the basic RCPSP, it is assumed that the amount of demand of an activity for renewable resources during processing is constant. In other words, the demand of activities for resources during the implementation process does not change from a period to another. This assumption can be turned into a more general mode by considering the variable demand in the time unit. Regarding the basic RCPSP, $r_{j k}$ is indicative of the consumption amount of recourse $k$ by activity $j$ in each period. If it is aimed to regard the variable demand, $r_{j k}$ must be replaced by $r_{j k t}$, which is indicative of the amount of demand of activity $j$ for renewable resource $k$ at the $t^{\text {th }}$ period of its processing time (Hartmann \& Briskorn, 2010).

In their scheduling problem, Cavalcante et al. (2001) presented a work profile for each activity to use the human resources, demonstrating that a different number of workers was used during the implementation of each activity. Meanwhile, the number of available workers in each day was a constant amount. 
A mode of project scheduling problem in software companies was considered by Drezet and Billaut (2008), where the resources related to the execution of activities were employees, and the need of activities for these resources depended on time. Need of each activity to employees in each period varies in a range with a maximum and minimum value. In the Hartmann (2013), scheduling of experiments related to a medical research project was evaluated, where two types of resources were required to perform the experiments. The first resource was the researcher, who must be present during the test process. However, the second resource was laboratory equipment, which was only required on the final day of the experiments, and therefore, was regarded as the resource with variable demand per time unit.

\subsubsection{Other characteristics of activities}

One of the essential pillars of projects is when all of the activities are performed and the project is completed. Therefore, reducing the execution time of the project can be significantly interesting to project owners. Reduction of the duration can be carried out in various forms, including the use of additional shifts or working overtime and/or allocation of a greater amount of resources, which is associated with increased costs and investments (Ahn \& Erenguc, 1998). Activity crashing is a technique used to reduce the implementation time of the project through the decrease of duration of critical activities by allocating higher costs (Nonobe \& Ibaraki, 2006). This technique is used in many studies related to project scheduling, such as Ahn and Erenguc (1998), Göçken (2013) and Kang and Choi (2015) as well as especially the researches in which there is a tradeoff between time and cost. In addition, Drexl et al. (2000) presented a new concept with the title of forbidden periods, in which a set of time periods exist for each activity when the activities cannot be performed. These forbidden periods are due to the nature of the activities and are not related to the work calendar or any other limitation. In some problems, transferring from one activity to another is in a way that requires the implementation of some operations. In other words, there is a considerable workload in performing operations between activities, which cannot be neglected. Some of these operations include the transferring of resources or installing and setting up some resources, such as machinery. Therefore, Čapek et al. (2012) considered a mode of project scheduling problem, in which one resource along with positive and negative time lags and sequence-dependent setup times was involved. Sequence-dependent setup times are responsible for covering the time required to change equipment or launch a machine between two different activities.

\subsection{Objective function type}

Generally, mathematical optimization models have defined objective function, which is determined in proportion to the objective of the decision maker. In project scheduling problems, the start time of activities must be determined with regards to a specific objective. Since project owners follow their goals to determine optimal scheduling, various objective functions are evaluated during the time of theoretical development of RCPSP, which are categorized in this section:

\subsubsection{Time-based objective functions}

Minimization of the project completion time (Cmax) is the most popular type of objective function in the RCPSP literature. In this type of objective functions, which is also regarded as the objective function of the basic RCPSP, activities of the project are scheduled in a way that completion time of the project reaches the minimum amount. Taking into account the uncertainty about the duration of activities in the scheduling problem, Creemers (2015) presented a model, which minimized the expected completion time of the project. In addition to the objective function of minimizing Cmax, minimizing lateness, tardiness and earliness are regarded as other time-based objective functions. The lateness for activity $j$, which is shown by $L_{j}$, indicates the amount of difference in the completion time $C_{j}$ from a specific delivery time $d_{j}$, which is equal to $L_{j}=C_{j}-d_{j}$. Tardiness $T_{j}$ is similar to $L_{j}$, except for the fact that it cannot allocate negative values to itself and is defined as $T_{j}=\max \left\{0, C_{j}-d_{j}\right\}$. Earliness, shown by $E_{j}$, expresses 
the time that the activity is finished earlier than the determined time of $d_{j}$, estimated in the form of $E_{j}=$ $\max \{0, d j-C j\}$. Viana and de Sousa (2000) presented the multi-objective scheduling problem, in which minimization of the weighted lateness was used as one of the objective functions of the problem. It is worth noting that this type of objective function generalizes the objective of reducing the project completion time. In another research, Neumann et al. (2002) described the method to minimize the maximum lateness and minimize the total weighted tardiness in scheduling problem. Drezet and Billaut (2008) developed the project scheduling problem with the involvement of multi-skilled human resources and aim of minimizing the maximum lateness. The objective function of minimizing the maximum lateness is one of the most widely used time-based functions, which was also applied in Słowinski (1981). Given the facing of managers with the problem of decision making about the allocation of resources for minimizing the mean tardiness per each project or completion time of all projects in multiproject scheduling problems, Browning and Yassine (2010) considered the resource-constrained multiproject scheduling problem with two objectives of minimization of project lateness and portfolio lateness. Xiao et al. (2014) also followed a bi-objective project scheduling problem, which minimized not only the project completion time but also the total tardiness. These objective functions were considered by Xiao et al. (2016). In some conditions, it is necessary to minimize the duration between the completion time and deadline of activities. This type of scheduling is recognized as earliness-tardiness project scheduling problem.

\subsubsection{Economic objective functions}

Cost-based objective functions: Another objective function proposed in RCPSP is the cost-based objective, including the costs of implementation and completion of project. In most of the project scheduling problems, there is a tradeoff between cost and time. For instance, in multi-mode project scheduling problems, a definite processing duration and cost exist for each method to perform the activity. Since completion of an activity in a shorter duration is often associated with increased costs, a problem with the title of "time-cost tradeoff problem" is formed. Berthaut et al. (2014) followed the time-cost tradeoff problem by considering the acceleration of performing the project through overlapping of sequential activities and costs caused by parallel performing of these activities. Choi and Park (2015) defined several stages in project such a way that the tardiness in each stage was associated with penalty cost. Moreover, since the processing time of activities can be reduced by consuming more resources, an objective function is presented, which minimizes the total penalty cost in addition to the total cost of activity crashing. Considering the uncertainty in activities processing time, Kang and Choi (2015) considered a stochastic time-cost tradeoff problem, which determined how much duration of activities could be reduced to minimize the expected total costs of reducing the execution time of activities and tardiness. In some other studies, activities are scheduled in a way that the total cost of the project implementation is minimized. Depending on various conditions, these costs are formed of various costs. Given the importance of activities implementation cost for the contractor in a multi-project environment, Liu and Zheng (2008) minimized the fixed cost of implementing the project activities and holding costs of completed activities of projects in their model. This type of objective function was also assessed in Zhenyuan and Hongwei (2006) and Montoya-Torres et al. (2012) and also, the solution method was provided. In addition, Karshenas and Haber (1990) considered only the cost of all consumed resources of a project, which must be minimized. Maniezzo and Mingozzi (1999), Möhring et al. (2001), and Möhring et al. (2003) regarded $\operatorname{cost} C_{j t}$ for activity $j$, value of which depended on the initiation time $t$. The objective function of this type of research is minimization of all of these costs. Rajeev et al. (2015) tried to schedule activities in a way that the total weighted penalty cost of earliness-tardiness of the project was minimized according to the constraints of precedence relationships and resource constraints.

Net Present Value (NPV): One of the objective functions assessed in RCPSP is the objective of Net Present Value (NVP) maximization. Since costs and revenues of activities are occurred during time, considering the NVP instead of total costs or revenues can be significantly effective. Cash outflows or costs are occurred due to performing activities and consuming resources and On the other hand, cash 
inflows or revenues are earned as a result of completion of specific sections of the project. Cash flows caused by activity $j$ can occur at several points of the implementation time of activity $j$. However, they can be combined in a single cash flow occurred in the beginning or at the end of activity $j$. Considering these issues can lead to problems with the objective of maximizing the NVP with the constraints of the basic RCPSP. Optimization of the NVP for project scheduling problems was first introduced by Russell (1970), and greatly developed over time. Shavandi et al. (2012) regarded the duration of activities as triangular fuzzy numbers, and evaluated the maximization of NVP in a fuzzy environment. In addition, Wiesemann et al. (2010) maximized the expected project NVP, when the processing time of activities and cash flows were described by a discrete set of scenarios with the definite probability of occurrence. Moreover, Sobel et al. (2009) considered the maximization of the expected NVP in the uncertainty environment. In the MRCPSP, Ulusoy et al. (2001) expressed four payment models, which were practically used to discount cash flows. In the lump-sum payment model, all payments are made by customer to contractor immediately and all at once after the successful completion of the project. In the second model of payments entitled payments at event occurrences, payments are made in a set of previously determined event nodes. In the third model, known as equal time intervals, the customer makes $H$ payments in $H-1$ equal periods during the project duration with the final payment being immediately after the completion of the project. In the final model with the name of progress payment, the contractor receives the payments from the customer at determined time intervals until the completion of the project. For instance, payments might be at the end of each month for the work done in that month and according to an agreed profit rate between the customer and the contractor. It should be noted that MRSPSP with considering the discounted cash flows is known as the Multi-mode Resource-Constrained Project Scheduling Problem with Discounted Cash Flows (MRCPSPDCF). One of the specific problems in project scheduling is resource investment problem, in which the accessibility level to resources is regarded as decision variable, and a scheduling timetable for activities along with an accessibility level to resources are obtained according to the optimization of a specific objective. Therefore, Najafi and Niaki (2005) considered a resource investment problem, aiming to maximize the project NVP. In addition, they proposed a solution method for this type of problems, which are recognized as resource investment problem with discounted cash flows. Leyman and Vanhoucke (2015) and Leyman and Vanhoucke (2016) used the payments at activities completion times model to maximize the NVP, where it was assumed that cash inflows and outflows for each activity occur at its completion time. Presenting their model, Khoshjahan et al. (2013) tried to minimize the present value of earliness-tardiness penalty costs through defining a deadline for each activity. In their research, the mathematical programming model was proposed first, followed by the application of two solution algorithms (i.e., genetics and simulated annealing) to solve this NP-Hard problem.

\subsubsection{Resource-based objective functions}

Renewable resource objective functions: In the basic RCPSP, the project completion time must be minimized with regard to the renewable resources constraint. The dual of this problem is Resource Investment Problem (RIP), which was first introduced by Möhring (1984). In RIP, the costs related to the provision of a specific level of capacity must be minimized according to the deadline set for the project. The objective function of this type of problems is minimizing the sum of costs of access to all resources or $\sum_{k} C_{k}\left(R_{k}\right)$, where $C_{k}$ is a non-decreasing discrete cost function of resource $k$, and capacity levels $R_{k}$ are obtained as decision variables through solving the model (Hartmann \& Briskorn, 2010). In some studies, such as Shadrokh and Kianfar (2005), Shadrokh and Kianfar (2007), Liu et al. (2015), and Yuan et al. (2015), resource investment problem has been considered by allowing the tardiness. In this regard, if the completion time of the project is extended more than the defined deadline, penalty cost must be paid, which is added to the objective function of the problem. Najafi and Niaki (2006) considered resource investment problem with discounted cash flows, objective function of which encompassed of the fixed cost of performing activities, cash receipts and the costs due to the required level of resources. In addition to considering the discounted cash flow in their objective function for resource investment problem, Najafi and Azimi (2009) also regarded the tardiness cost in the objective. 
Xiong et al. (2011) evaluated the Stochastic Resource Investment Project Scheduling Problem (SRIPSP), in which three objectives of project completion time, cost and robustness were simultaneously considered. Another mode of RIPSP problem is known with the title of Extended Resource Investment Project Scheduling Problem (ERIPSP), in which the duration of activities depends on the amount of allocated resources. Xiong et al. (2014) assessed a mode of ERIPSP entitled Stochastic Extended Resource Investment Project Scheduling Problem (SERIPSP), in which three objectives of minimizing the project completion time and cost, as well as maximizing the robustness were followed. One of the most important objectives in project management is achieving a stable level of required resources in each period, known as resource leveling problem. The main objective of this type of problems is minimizing the changes in the level of consumed resources from a period to another with a deadline constraint. Neumann and Zimmermann (1999) and Neumann and Zimmermann (2000) pointed out three common objective functions in this type of problems:

- In the first objective function, maximum changes in the resources is minimized, which was also used in Wang et al. (2008).

- In the second objective function, it is aimed for the amount of consumed resources not to exceed a certain level. In other words, the total amount of resources that exceed the permitted level is minimized. This type of objective function was recently applied in studies, such as Bianco et al. (2016) and Tran et al. (2016).

- In the third objective function, the total changes in the consumed resource level in each period is minimized compared to that of in the previous period, which was exploited in Li et al. (2010) and Nikoofal Sahl Abadi et al. (2016).

Nübel (2001) expressed a generalized mode of resource investment problem with the title of resource renting problem. In this type of problems, it is assumed that each unit of resource $k$ is rented in each period with the fixed $\operatorname{cost} C_{k}^{f}$ and the variable $\operatorname{cost} C_{k}^{v}$. Therefore, cost of renting $a$ unit of resource $k$ for $t$ periods is equal to $a\left(C_{k}^{f}+t C_{k}^{v}\right)$. Costs of delivering resources to the project site can be regarded as fixed cost, whereas variable cost is indicative of the actual cost for rent. While $C_{k}^{v}=0$ is observed in this type of problems, resource renting problem will be turned into resource investment problem.

Non-renewable resource objective functions: Similar to the dual concept for resource investment problem, the amount of consumed non-renewable resources can be minimized here through imposing a deadline on the project. One of the project scheduling problems with objectives based on non-renewable resources is the discrete time/cost tradeoff problem. Similar to Vanhoucke et al. (2002) and Akkan et al. (2005), in this type of problems, it is assumed that the processing duration of the project activities is discrete and a non-decreasing function of the amount of non-renewable resources. Najafi et al. (2011) evaluated a type of Project Scheduling and Material Ordering Problem (PSMOP), where the total holding and ordering costs during the project implementation were minimized. Khalilzadeh et al. (2012) also regarded a type of resource investment problem, in which tardiness was allowed for renewable resources and the total costs of consuming non-renewable resources and penalty cost caused by tardiness of renewable resources were minimized in the objective function. Damak et al. (2013) analyzed a type of MRCPSP, which helped the minimization of the project completion time and cost of non-renewable resources.

\subsubsection{Other objective functions}

In some cases, the decision maker might have specific objectives and make optimal scheduling to achieve them. In addition to time and cost, the factor of quality can also be regarded as an important objective of a project. Quality is generally considered along with cost or time or both. The Discrete Time-Cost-Quality Tradeoff Problem (DTCQTP) is one of the most applicable project scheduling problems, in which it is aimed to obtain the optimal scheduling timetable from the combination of objectives of minimizing the completion time and cost and maximizing the quality. In this type of problems, each 
activity has several implementation modes with each having its own required resources. This property is associated with the effectiveness of selecting the implementation mode of activities on time, cost and quality. Maghsoudlou et al. (2016) also evaluated a resource-constrained project scheduling problem with multiple modes and multi-skill resources as well as considering three objective functions. In the first objective function, the project completion time was minimized. In the second objective function, the total cost of assigning workers to skills was minimized, and the quality of processing activities was maximized with the third objective function. During the implementation of the project, some interruptions may occur, which disrupts project scheduling. This type of interruptions cannot be predicted when the scheduling timetable is obtained. Therefore, a project manager might be willing to determine a stable scheduling timetable, in which interruptions could have little impact. As a result, the related objective functions must be used to prepare a stable and robust scheduling timetable. In this regard, Abbasi et al. (2006) presented a RCPSP model with two objectives, where the project implementation time was minimized in the first objective function and maximization of floating time for increase of scheduling robustness were considered as the second objective function. Similar to Abbasi et al. (2006), Hao et al. (2014) presented a project scheduling problem with two objectives of minimizing the project completion time and maximizing the scheduling robustness, with the difference that Hao et al. (2014) considered the scheduling robustness criteria as a weighted equation with regard to the number of successor activities. Khemakhem and Chtourou (2013) reviewed some criteria for scheduling robustness presented in the literature and also proposed some new criteria. In some cases, unexpected events, such as disruption of project time and consumed resources, might occur during the implementation of the project, leading to problems in the primary determined scheduling. In such conditions, scheduling must be carried out again, which could result in some changes in the properties of the problem. For instance, some of the completed activities might be neglected and some ongoing activities must be assumed fix. In addition, the accessibility level to resources might be changed or be converted from stable amount to the time-depending amount. In this mode and with regard to the objectives of the decision maker, various objective functions can be used for re-scheduling. Considering MRCPSP, Deblaere et al. (2011) used an objective function for re-scheduling that minimized the difference between the start time of activities in the primary scheduling and start time of activities in rescheduling along with the costs caused by change of method in non-completed activities in rescheduling timetable. Chen and Zhang (2014) also attempted to minimize the total weighted absolute difference between the start time and deadline of activities. Chakrabortty et al. (2016) proposed a methodology for rescheduling problem, where in addition to the minimization of the project completion time, the weighted difference of the activities completion time in the rescheduling timetable was minimized, compared to that of in the nominal scheduling. In this regard, positive or negative difference has its own relevant penalty.

\subsubsection{Multi-objective problems}

In some cases, the decision maker might consider several performance criteria or objective functions to determine the optimal scheduling timetable. In this case, combination of two or several objective functions can be applied. Since the considered objectives are often in conflict with each other, a multiobjective scheduling model can be applied to create the necessary tradeoff between the objectives.

\subsection{Availability level of information}

The aim of project scheduling is providing a baseline schedule for more accurate control of the project and more easy planning for project success. However, it is noteworthy that this scheduling timetable must be obtained before the start of the project and its accuracy depends on the information used to provide the scheduling timetable. Availability level of required information can be full or limited. If the required information is complete, the obtained scheduling timetable will be optimal and valid. But in the case of having limited information, project scheduling must be analyzed in an uncertainty environment. 


\subsubsection{Deterministic}

Similar to the basic RCPSP, which assumed all information to be complete and certain, many studies in the field of project scheduling have considered that complete information about parameters exists and a basic scheduling timetable is prepared in a deterministic environment for applying in the future. However, since the basic scheduling timetable is obtained before the project implementation and is regarded as a form of prediction, the assumption of data certainty in the real world is not completely correct. Therefore, some approaches have been recently used for preparing project scheduling timetable in uncertainty environment, which will be explained in the following.

\subsubsection{Non-deterministic}

Resource-constrained project scheduling problems are often faced with significant uncertainties, negligence of which might cause several problems in the implementation phase. These uncertainties can be related to at least one of the following sources:

- Activities might be performed in a shorter duration or longer than the estimated amount.

- The resources and materials might not be available at the time of need.

- It might be inevitable to change the start time and determined deadlines of activities for any reason.

- In another mode, new activities might be added or some activities might be eliminated due to changes in the project scope.

- In addition, unpredictable natural disasters, such as weather and climate, might cause significant delays.

- And similar issues.

Disrupted scheduling leads to more costs due to the loss of the determined deadlines, useless of resources, more work in process and tense system environment (Goldratt, 1997). Therefore, solutions must be presented to deal with these uncertainties. As a result, various strategies have been evaluated in studies for project scheduling in the uncertainty environment. In this regard, five important approaches are introduced in the following.

Reactive scheduling: This approach is applied during the project implementation and is based on timely information. In this approach, uncertainty is not involved in preparing of scheduling timetable. Nevertheless, basic schedule is reviewed and reoptimized in case of occurring an unexpected event. In terms of reactive scheduling, two questions might be raised:

- First, when do we need a new scheduling? A new scheduling can be prepared at any time of occurring of unexpected event (see, Wu et al., 1993; Bierwirth \& Mattfeld, 1999), or, similar to Church and Uzsoy (1992), be created in predetermined intervals, or, similar to Vieira et al. (2000), be formed when a certain threshold of deflection is reached. while reactive scheduling requires a significant processing time along with various successive calculations, one of the most important benefits of this method is immediate reaction to unexpected events.

- The second question is that how is a new scheduling timetable created? Various strategies can be applied to form a new scheduling, one of the most common and simple of which is the right shift rule (Sadeh et al., 1993; Smith, 1995). In this approach, activities affected by scheduling failure are transferred forward in time. Another applicable approach is complete scheduling of that section of the project, which is not been implemented at time of occurrence of unexpected event. This rescheduling can have various objectives. In studies, such as Lambrechts et al. (2008), rescheduling was carried out with the objective of minimizing the total weighted difference between the start time of activities in rescheduling and start time of activities in the basic schedule. Similar to this objective, Suwa and Morita (2016) tried to minimize tardiness at the 
start time of activities in rescheduling, compared to the start time of tasks in the basic schedule. In Chakrabortty et al. (2016), rescheduling was performed to minimize the project completion time and weighted penalty of deflection in project complete time in rescheduling timetable, compared to that of in basic schedule.

Stochastic scheduling: In this approach, it is assumed that parameters of project scheduling problem are probabilistic. The literature related to stochastic project scheduling can be categorized into four problems of Stochastic Resource-Constrained Project Scheduling Problem (SRCPSP), project scheduling problems with stochastic activity interruptions, stochastic discrete time/cost trade-off problem and stochastic project scheduling problems with economic objective functions.

Stochastic resource-constrained project scheduling problem has the same assumptions as the basic RCPSP, with the difference that the processing duration of activities is assumed to be probabilistic. In other words, the aim of SRCPSPs is scheduling the project activities with a probabilistic duration, in a way that the expected project completion time is minimized according to the precedence relationships and renewable resources constraints. Valls et al. (1999) regarded a type of uncertainty for RCPSP, in which activities had both deterministic and non-deterministic duration. In other words, the first part of processing time of activity $j$ is considered deterministic and equal to $d_{j l}$. After that, it is assumed that a disruption with duration of $w_{j}$ occurred and the remaining processing time of activity after the disruption occurrence is assumed non-deterministic and equal to $d_{j 2}$. For instance, obtaining necessary licenses before the completion of this activities can be pointed out for such disruptions, implementation of which requires a specific duration. This type of problems is recognized as project scheduling problems with stochastic activity interruptions.

Another category of stochastic problems is related to stochastic discrete time/cost trade-off problems. Wollmer (1985) regarded a stochastic mode for linear time/cost tradeoff problem, in which activities had $Y_{j}+\xi_{j}$ duration. In this respect, $Y_{j}$ is the duration of processing activity $j$, for which crash duration $l_{j}$ and normal duration $u_{j}$ are considered as its upper and lower bounds, respectively. In addition, $\xi_{j}$ is a discrete random variable for time and independent of value $Y_{j}$. Given the implementation of each activity $j$ with $\operatorname{cost} C_{j}$, which depends on the duration of activity $j$ (known as $Y_{j}$ ), it is aimed to determine $Y_{j}$ and start time of activities in a way that the expected completion time of the project is minimized according to budget consideration or in contrast, minimum cost is obtained according to determined expected time for project completion.

Another category of stochastic project scheduling problems is related to stochastic project scheduling problems with economic objectives. In this regard, Ke and Liu (2005) evaluated project scheduling problem with stochastic durations for activities and with the objective of minimizing the total cost under completion time constraints. They presented three different stochastic models with the titles of expected cost model, alpha-cost model and probability maximization model. On the other hand, Sobel et al. (2009) and Wiesemann et al. (2010) aimed to maximize expected NVP of the project in a condition that the duration of activities and cash flows were defined in the form of a discrete set of scenarios, which occur with specific probabilities. In addition, Chen et al. (2010) and Chen and Zhang (2012) assessed Stochastic Multi-mode Resource-Constrained Project Scheduling Problem with Discounted Cash Flows (SMRCPSPDCF), in which the duration of activities and costs were defined with random variables, aiming to determine an optimal scheduling in a way that the expected NPV of cash flows was maximized.

Fuzzy scheduling: In some cases, lack of historical data might lead to inability to determine the probability distribution for duration of activities. In addition, duration of activities is estimated by experts often under unique conditions of the project and its non-repeatability. In fact, managers of the project are faced with ambiguous judgmental statements. In such conditions, where we deal more with ambiguity than uncertainty, the literature about fuzzy set scheduling indicates that use of fuzzy numbers is 
more preferred for modeling, compared to random variables. In other words, these values use membership functions based on possibility theory as a replacement for probability distributions (Herroelen \& Leus, 2005). Fuzzy theory was first introduced by Zadeh (1965), and first studies on application of fuzzy condition in project scheduling problem was conducted by Prade (1979) and Chanas and Kamburowski (1981), where fuzzy numbers were used with triangular membership functions based on optimistic, probable and pessimistic estimates for duration of activities. Xu and Feng (2014) developed the MRCPSP for a large-scale construction project in a way that scheduling was performed through the optimization of cost/weighted completion time/quality tradeoff in a random fuzzy environment. In a complicated environment, where there are more than one type of uncertainty, Ke and Ma (2014) presented three time-cost tradeoff models with the titles of expected cost minimization model, $(\alpha, \beta)$ cost minimization model and chance maximization model, in which the project environment was described by introducing the random fuzzy theory. Moreover, Xu et al. (2015) presented a bi-level model with several decision makers for a project scheduling problem in a random fuzzy environment, where both interests of the project owner (maximization of benefit and minimization of project completion time) and contractor (minimization of costs) were considered. Cheng et al. (2016) introduced a new optimization model with the title of Fuzzy Clustering Chaotic-based Differential Evolution (FCDE) for solving Resource Leveling (FCDE-RL), where FCDE was developed by integration of differential evolution with c-mean fuzzy clustering and chaos techniques for solving complex optimization problems. Furthermore, Tran et al. (2016) used the same technique (FCDE) for Multiple Resources Leveling in Multiple Projects Scheduling Problem (FCDE-MRLMPSP).

Proactive (robust) scheduling: In contrast to concept of reaction scheduling, active scheduling aims to predict the events that cause project tardiness through the creation of a stable schedule. This type of scheduling helps minimizing the effects of unexpected events on the main performance criteria, such as project completion time. Application of this method enables project managers to design stable scheduling so that some of the activities could be delayed while the completion time of the project could remain fixed (Palacio \& Larrea, 2016). Creation of a robust scheduling is possible through various methods. In general, there are three approaches to create robust scheduling timetable in the literature, which are shown in Fig. 2 (Lambrechts et al., 2011).

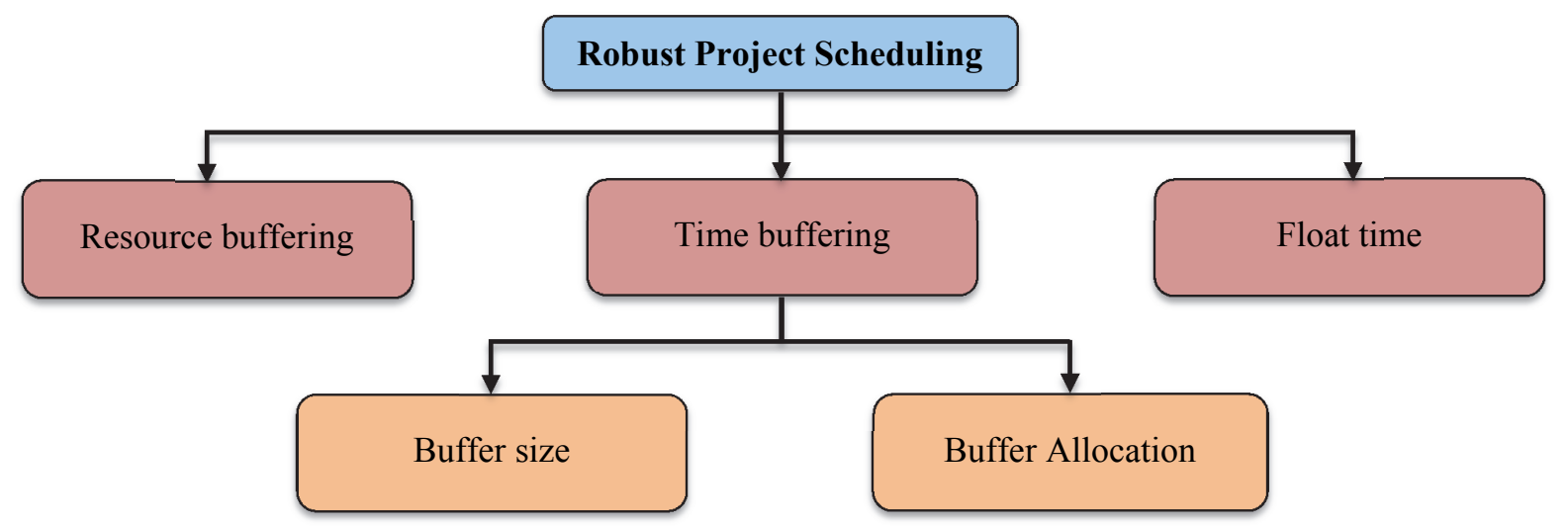

Fig. 2. Robust scheduling methodologies (Lambrechts et al., 2011)

In contrast to buffer-based approaches, floating-based approach aims to produce a stable scheduling without adding additional time in order to maximize the floating of activities. Al-Fawzan and Haouari (2005) presented a bi-objective model, which not only minimizes the project completion time, but also maximizes the scheduling robustness to achieve a high-quality scheduling. Similarly, Abbasi et al. (2006) proposed a bi-objective model for RCPSP, with the difference that in the latter, robustness was evaluated in the form of the floating time of the project. In line with creating stability in RCPSP, Chtourou and Haouari (2008) presented a two-stage-priority-rule based algorithm and reviewed various robustness criteria based on free activity slack. 
Another method to create robust project scheduling is the time buffer insertion, which means adding a percentage of activity implementation time to the activity duration. Here, the aim is to use buffer times to protect the scheduling timetable from the failures and attract them to prevent distribution over the total project. In this approach, two important decisions must be made; the first decision is about determining the total buffer times allocated to activities, value of which determines total robustness cost. The second decision is about the fact that how much buffer time is allocated to each activity and which activities are actually involved. Van De Vonder et al. (2005), Van De Vonder et al. (2006a), Van De Vonder et al. (2006b) and Van De Vonder et al. (2007b) developed several exact and near optimal methods to insert the time buffers in an initial scheduling according to the objective of minimizing robustness cost. Among these methods, the Starting Time Criticality (STC) heuristic method has yielded positive results, despite its simple assumptions and structure.

Use of resource buffering, which is regarded to ensure the access to resources, is interpreted as the allocation of additional resources to each activity. In other words, in this method, a percentage of resource capacity is considered as reserved, and planning is performed for the remaining capacity. For strengthening of project scheduling timetable in the presence of disruptions, such as failure or lack of accessibility to resources, Lambrechts et al. (2011) applied resource buffering method to control the uncertainty related to lack of supply of resources during the project.

In various studies, different robustness objective functions have been used along with the minimizing completion time objective function in order to obtain a stable scheduling. Therefore, Khemakhem and Chtourou (2013) reviewed the main robustness criteria exploited in the literature and introduced several new criteria. Moreover, Lamas and Demeulemeester (2015) first defined a new robustness criterion with the title of confidence level and in form of probabilistic, followed by introducing a branch and cut method to solve the problem. Afshar-Nadjafi (2016) regarded the robust project scheduling problem with the existing reworks during the implementation of the project, and presented a recursive method to solve the problems with time buffer between activities (as an improving method) to enhance the robustness of a basic scheduling timetable. On the other hand, Palacio and Larrea (2016) proposed an exact method using lexicographic approach to solve two Mixed-Integer Programming (MIP) models of RCPSP problem, where the first model tried to minimize the project completion time, whereas the second model aimed to maximize the scheduling robustness.

There is another category of problems with the title of proactive-reactive project scheduling, which includes both proactive and reactive scheduling phases. In other words, at first, in the active scheduling phase, it is aimed to create a scheduling which is preferably resistant to unexpected events and disruptions. After the implementation of the project according to the prepared scheduling, when an event occurs, the reactive scheduling phase is implemented, if necessary, to modify the basic scheduling timetable. This type of problems is categorized by Van De Vonder et al. (2007b).

Sensitivity analysis: Another applicable approach in uncertainty condition is sensitivity analysis, which answers the questions starting with "What if...?" in conditions where parameters are changed. In this method, researchers mainly attempt to answer some basic questions, such as:

- When does a basic scheduling remain optimal?

- When does the value of objective function remain optimal?

- What are the changing intervals of the parameters, in which the solution remains optimal?

- What is the new optimal cost in case of occurrence of a specific change in a parameter?

- What is the new optimal solution in case of occurrence of a specific change in a parameter?

- What type of sensitivity analysis should be utilized to evaluate the stability of optimal solution?

- And etc. 
The majority of available studies in context of sensitivity analysis of scheduling problem, have been conducted on sensitivity analysis of machinery and workshop scheduling and in environment of production systems. Therefore, raising and answering similar questions about scheduling in project environment can be one of the interesting research fields for future studies. In addition, some topics can be discussed in this field that while have never been investigated, and seem to be extremely important. One of these topics is determining the permitted changing intervals of parameters, in a way that the optimality of full rescheduling is guaranteed by using simple modification techniques, such as right shift method (Herroelen \& Leus, 2005).

\section{Summary of RCPSP researches}

Concepts and definitions related to RCPSP along with some developments were introduced in the previous section. In addition to extended development of this topic, it was attempted to fully cover the literature in this field. Therefore, all the relevant researches were categorized from four main dimensions of resources, characteristics of activities, type of objective function and availability level of information. With regard to this categorization, it could be stated that despite serious developments in project scheduling problem, investment can be made in some areas and assumptions of RCPSP and new studies can be conducted. Some researches on RCPSP are summarized in Table 1 to conclude and present research gaps for future studies in this area.

\section{Table 1}

Resource constrained project scheduling models

\begin{tabular}{|c|c|c|c|c|}
\hline Article & Resource type & Activity characteristics & Objective function & $\begin{array}{l}\text { Cer- } \\
\text { tainty }\end{array}$ \\
\hline Słowiński (1980) & RR/NRR/DCR & PRN/MM & $\mathrm{TBO} / \mathrm{Cmax} / \mathrm{CBO}$ & $\overline{D S}$ \\
\hline Słowinski (1981) & RR/NRR/DCR & PRN/MM & MO & DS \\
\hline Möhring (1984) & $\mathrm{RR}$ & DRD & $\mathrm{Cmax} / \mathrm{RRO}$ & DS \\
\hline Wollmer (1985) & DRD & DRD & Cmax & SS \\
\hline Bartusch et al. (1988) & RR & DRD & Cmax & DS \\
\hline Karshenas and Haber (1990) & RR/NRR & DRD & $\mathrm{CBO}$ & DS \\
\hline Davis et al. (1992) & RR & DRD & $\mathrm{MO}$ & DS \\
\hline Boctor (1993) & RR & MM & Cmax & DS \\
\hline Hapke and Slowinski (1993) & RR & DRD & MO & FS \\
\hline Wang et al. (1993) & RR/NRR & MM & $\mathrm{MO}$ & FS \\
\hline Hapke et al. (1994) & RR & DRD & $\mathrm{TBO} / \mathrm{Cmax}$ & FS \\
\hline Boctor (1996) & RR & MM & Cmax & DS \\
\hline $\begin{array}{l}\text { Demeulemeester and Herroelen } \\
\text { (1996) }\end{array}$ & RR & PRN & Cmax & DS \\
\hline Ulusoy and Özdamar (1996) & RR/NRR/DCR & MM & $\mathrm{MO}$ & DS \\
\hline Nabrzyski and Weglarz (1997) & RR/NRR/DCR & MM & $\mathrm{MO}$ & DS \\
\hline $\begin{array}{l}\text { Nudtasomboon and Randhawa } \\
\text { (1997) }\end{array}$ & $\mathrm{RR} / \mathrm{NRR} / \mathrm{DCR}$ & $\mathrm{PRN} / \mathrm{MM}$ & $\mathrm{TBO} / \mathrm{CBO} / \mathrm{RRO}$ & DS \\
\hline Sung and Lim (1997) & RR & MM & Cmax & DS \\
\hline Ahn and Erenguc (1998) & RR & $\mathrm{MM} / \mathrm{AC}$ & $\mathrm{CBO}$ & DS \\
\hline Demeulemeester et al. (1998) & NRR & MM & NRRO & DS \\
\hline Hapke et al. (1998) & RR/NRR/DCR & MM & MO & DS \\
\hline Konstantinidis (1998) & RR/NRR/DCR & $\mathrm{AC}$ & $\mathrm{CBO}$ & DS \\
\hline De Reyck and Herroelen (1999) & RR/NRR/DCR & $\begin{array}{c}\text { MM/RV/OC(Activity } \\
\text { overlaps) }\end{array}$ & Cmax & DS \\
\hline Maniezzo and Mingozzi (1999) & DRD & DRD & $\mathrm{CBO}$ & DS \\
\hline $\begin{array}{l}\text { Neumann and Zimmermann } \\
\text { (1999) }\end{array}$ & RR & DRD & $\mathrm{RRO}$ & DS \\
\hline Valls et al. (1999) & $\mathrm{RR}$ & DRD & TBO & SS \\
\hline Drexl et al. (2000) & OR(Partially renewable) & MM & $\mathrm{CBO}$ & DS \\
\hline $\begin{array}{l}\text { Neumann and Zimmermann } \\
(2000)\end{array}$ & RR & DRD & NPV/RRO & DS \\
\hline Viana and de Sousa (2000) & RR/NRR & MM & $\mathrm{MO}$ & DS \\
\hline Cavalcante et al. (2001) & RR & RV & Cmax & DS \\
\hline Nübel (2001) & RR & DRD & $\mathrm{CBO}$ & DS \\
\hline
\end{tabular}




\begin{tabular}{|c|c|c|c|c|}
\hline Article & Resource type & Activity characteristics & Objective function & $\begin{array}{l}\text { Cer- } \\
\text { tainty }\end{array}$ \\
\hline Ulusoy et al. (2001) & RR/NRR/DCR & MM & NPV & $\overline{\mathrm{DS}}$ \\
\hline Haouari and Al-Fawzan (2002) & $\mathrm{RR}$ & DRD & $\mathrm{MO}$ & PS \\
\hline Vanhoucke et al. (2002) & NRR & $\begin{array}{l}\text { MM/AC/OC(Time-switch } \\
\text { constraints) }\end{array}$ & $\mathrm{CBO}$ & DS \\
\hline Möhring et al. (2003) & DRD & DRD & $\mathrm{CBO}$ & DS \\
\hline Akkan et al. (2005) & DRD & MM & $\mathrm{CBO}$ & DS \\
\hline Al-Fawzan and Haouari (2005) & RR & DRD & MO & PS \\
\hline Hsu and Kim (2005) & RR & MM & $\mathrm{RRO}$ & DS \\
\hline Ke and Liu (2005) & DRD & DRD & $\mathrm{CBO}$ & SS \\
\hline Najafi and Niaki (2005) & $\mathrm{RR}$ & DRD & NPV & DS \\
\hline Shadrokh and Kianfar (2005) & RR & DRD & $\mathrm{CBO}$ & DS \\
\hline Van de Vonder et al. (2005) & RR & DRD & $\mathrm{OO}($ Instability cost) & PS \\
\hline Abbasi et al. (2006) & RR & DRD & MO & PS \\
\hline $\begin{array}{l}\text { Buddhakulsomsiri and Kim } \\
\text { (2006) }\end{array}$ & $\mathrm{RR}$ & $\mathrm{PRN} / \mathrm{MM} / \mathrm{RV}$ & Cmax & DS \\
\hline Kadrou and Najid (2006) & RR(multi-skilled labor) & MM & Cmax & DS \\
\hline Najafi and Niaki (2006) & $\mathrm{RR}$ & DRD & NPV & DS \\
\hline Nonobe and Ibaraki (2006) & RR & $\mathrm{AC}$ & $\mathrm{CBO}$ & DS \\
\hline Van de Vonder et al. (2006a) & RR & DRD & MO & PS \\
\hline Zhang et al. (2006) & RR & PRN & Cmax & DS \\
\hline Zhenyuan and Hongwei (2006) & RR & DRD & $\mathrm{CBO}$ & DS \\
\hline Agarwal et al. (2007) & RR & DRD & Cmax & DS \\
\hline Ballestín (2007) & RR & DRD & $\mathrm{RRO}$ & DS \\
\hline $\begin{array}{l}\text { Buddhakulsomsiri and Kim } \\
\text { (2007) }\end{array}$ & RR & $\mathrm{PRN} / \mathrm{MM} / \mathrm{RV}$ & Cmax & DS \\
\hline Damay et al. (2007) & RR & PRN & Cmax & DS \\
\hline Shadrokh and Kianfar (2007) & RR & DRD & $\mathrm{CBO}$ & DS \\
\hline Van de Vonder et al. (2007a) & RR & DRD & $\mathrm{OO}$ (Instability cost) & RS \\
\hline Ballestín (2008) & RR & RV & $\mathrm{RRO}$ & DS \\
\hline Ballestin and Trautmann (2008) & RR & DRD & $\mathrm{TBO}$ & RS \\
\hline Chtourou and Haouari (2008) & RR & DRD & Cmax/OO(Robustness) & PS \\
\hline Creemers et al. (2008) & DRD & DRD & NPV & SS \\
\hline Drezet and Billaut (2008) & RR(Multi-skill) & $\mathrm{PRN} / \mathrm{RV}$ & $\mathrm{TBO}$ & DS \\
\hline Gourgand et al. (2008) & RR(Local and global) & $\begin{array}{c}\text { MM/OC(Multisite activi- } \\
\text { ties })\end{array}$ & Cmax & DS \\
\hline Lambrechts et al. (2008) & RR & DRD & $\mathrm{OO}$ (Instability cost) & RS-PS \\
\hline Liu and Zheng (2008) & RR & DRD & $\mathrm{CBO}$ & DS \\
\hline Shukla et al. (2008) & RR & DRD & Cmax & DS \\
\hline Vanhoucke and Debels (2008) & RR & PRN/OC(Fast tracking) & $\mathrm{Cmax} / \mathrm{RRO}$ & DS \\
\hline Wang et al. (2008) & RR & DRD & RRO & DS \\
\hline Ballestín et al. (2009) & RR & PRN & Cmax & DS \\
\hline Najafi and Azimi (2009) & RR & DRD & NPV & DS \\
\hline Najafi et al. (2009) & RR & DRD & NPV & DS \\
\hline Sobel et al. (2009) & DRD & DRD & NPV & SS \\
\hline Browning and Yassine (2010) & RR & DRD & $\mathrm{TBO}$ & DS \\
\hline Chai et al. (2010) & RR & $\mathrm{MM} / \mathrm{RV}$ & $\mathrm{MO}$ & DS \\
\hline Chen et al. (2010) & RR & MM & NPV & SS \\
\hline Fallah et al. (2010) & RR & PRN & $\mathrm{OO}($ Instability cost) & SS-PS \\
\hline Jing-wen and Hui-fang (2010) & RR/NRR & MM & $\mathrm{CBO}$ & DS \\
\hline Kanagasabapathi et al. (2010) & RR & DRD & $\mathrm{TBO}$ & DS \\
\hline $\begin{array}{l}\text { Klerides and Hadjiconstantinou } \\
\text { (2010) }\end{array}$ & DRD & $\mathrm{MM}$ & $\mathrm{Cmax} / \mathrm{CBO}$ & SS \\
\hline Li et al. (2010) & RR & DRD & $\mathrm{RRO}$ & DS \\
\hline Shadrokh (2010) & RR & PRN & $\mathrm{CBO}$ & DS \\
\hline Shi et al. (2010) & RR & DRD & Cmax & DS \\
\hline $\begin{array}{l}\text { Van Peteghem and Vanhoucke } \\
\text { (2010) }\end{array}$ & $\mathrm{RR} / \mathrm{NRR}$ & PRN/MM & Cmax & DS \\
\hline Wiesemann et al. (2010) & DRD & DRD & NPV & SS \\
\hline Bhaskar et al. (2011) & RR & DRD & Cmax & FS \\
\hline Deblaere et al. (2011) & RR/NRR & PRN/MM & Cmax & RS \\
\hline Heon Jun and El-Rayes (2011) & RR & DRD & MO & DS \\
\hline Huang and Ding (2011) & DRD & DRD & $\mathrm{CBO}$ & SS \\
\hline
\end{tabular}


F. Habibi et al. / Journal of Project Management 3 (2018)

\begin{tabular}{|c|c|c|c|c|}
\hline Article & Resource type & Activity characteristics & Objective function & $\begin{array}{c}\text { Cer- } \\
\text { tainty }\end{array}$ \\
\hline Lambrechts et al. (2011) & $\overline{\mathrm{RR}}$ & DRD & $\mathrm{OO}$ (Instability cost) & PS \\
\hline Li et al. (2011) & RR & PRN & Cmax & DS \\
\hline Najafi et al. (2011) & NRR & DRD & NRRO & DS \\
\hline Proon and Jin (2011) & RR & DRD & Cmax & DS \\
\hline Santos and Tereso (2011) & RR(multi-skill) & $\mathrm{MM}$ & $\mathrm{CBO}$ & DS \\
\hline Wu et al. (2011) & RR & DRD & Cmax & DS \\
\hline Xiong et al. (2011) & RR & DRD & $\mathrm{MO}$ & PS \\
\hline Zhu et al. (2011) & RR & PRN & Cmax & DS \\
\hline Abello et al. (2012) & RR & OC (Time-varying tasks) & MO & RS-PS \\
\hline Čapek et al. (2012) & RR & $\begin{array}{l}\text { OC(Sequence dependent } \\
\text { setup times) }\end{array}$ & Cmax & DS \\
\hline Chen and Zhang (2012) & RR & MM & NPV & SS \\
\hline $\mathrm{Hu}$ and Flood (2012) & RR & RV & MO & DS \\
\hline Janczura and Kuchta (2012) & DRD & DRD & $\mathrm{OO}$ & RS-FS \\
\hline Khalilzadeh et al. (2012) & RR/NRR & MM & $\mathrm{CBO}$ & DS \\
\hline Kyriakidis et al. (2012) & RR/NRR & MM & Cmax & DS \\
\hline Montoya-Torres et al. (2012) & RR & DRD & $\mathrm{CBO}$ & DS \\
\hline Ranjbar et al. (2012) & RR & DRD & RRO & DS \\
\hline Shavandi et al. (2012) & DRD & DRD & NPV & FS \\
\hline Vanucci et al. (2012) & RR(Agents) & $\mathrm{MM}$ & $\mathrm{MO}$ & DS \\
\hline Ballestín et al. (2013) & RR/NRR & MM & Cmax & DS \\
\hline Damak et al. (2013) & RR/NRR & $\mathrm{MM}$ & $\mathrm{MO}$ & DS \\
\hline Fink and Homberger (2013) & RR & DRD & NPV & DS \\
\hline Göçken (2013) & DRD & $\mathrm{AC}$ & $\mathrm{MO}$ & FS \\
\hline Hartmann (2013) & RR & RV & Cmax & DS \\
\hline Huang et al. (2013) & DRD & DRD & $\mathrm{CBO}$ & FS \\
\hline Khalili et al. (2013) & RR & DRD & $\mathrm{MO}$ & DS \\
\hline Khemakhem and Chtourou (2013) & RR & DRD & $\begin{array}{c}\text { Cmax/OO(Quality robust- } \\
\text { ness) }\end{array}$ & PS \\
\hline Khoshjahan et al. (2013) & $\mathrm{RR}$ & DRD & NPV & DS \\
\hline Li and Zhang (2013) & RR/NRR & MM & Cmax & DS \\
\hline Ranjbar et al. (2013) & RR & DRD & TBO & DS \\
\hline Wang et al. (2013) & RR & DRD & $\mathrm{MO}$ & DS \\
\hline Zamani (2013) & $\mathrm{RR} / \mathrm{NRR}$ & MM & $\mathrm{CBO}$ & DS \\
\hline Abello and Michalewicz (2014) & RR & OC (Time-varying tasks) & $\mathrm{MO}$ & RS \\
\hline Afruzi et al. (2014) & RR & $\mathrm{MM} / \mathrm{AC}$ & $\mathrm{MO}$ & DS \\
\hline Afshar-Nadjafi (2014a) & RR & MM & $\mathrm{RRO}$ & DS \\
\hline Afshar-Nadjafi (2014b) & RR & PRN & $\mathrm{CBO}$ & DS \\
\hline $\begin{array}{l}\text { Afshar-Nadjafi and Majlesi } \\
\text { (2014) }\end{array}$ & $\mathrm{RR}$ & $\begin{array}{c}\text { PRN/OC(setup time after } \\
\text { pre) }\end{array}$ & $\mathrm{Cmax}$ & DS \\
\hline Atli and Kahraman (2014) & $\mathrm{RR} / \mathrm{NRR}$ & $\mathrm{MM}$ & Cmax & FS \\
\hline Berthaut et al. (2014) & $\mathrm{RR}$ & $\begin{array}{c}\text { MM/OC(Activity over- } \\
\text { lapping) }\end{array}$ & $\mathrm{MO}$ & DS \\
\hline Can and Ulusoy (2014) & $\mathrm{RR} / \mathrm{NRR}$ & $\mathrm{MM} / \mathrm{RV}$ & $\mathrm{Cmax} / \mathrm{NPV}$ & DS \\
\hline Chakrabortty et al. (2014) & RR/NRR & MM & $\mathrm{Cmax}$ & DS \\
\hline Chen et al. (2014) & $\mathrm{RR} / \mathrm{NRR}$ & $\mathrm{MM}$ & Cmax/OO(Robustness) & PS \\
\hline Chen and Zhang (2014) & $\mathrm{RR} / \mathrm{NRR}$ & MM & TBO & $\begin{array}{l}\text { RS-FS- } \\
\text { PS }\end{array}$ \\
\hline Cheng et al. (2014) & RR & DRD & Cmax & DS \\
\hline Colak and Azizoglu (2014) & RR & $\mathrm{MM}$ & $\mathrm{RRO}$ & DS \\
\hline Creemers (2014) & RR & DRD & Cmax & SS \\
\hline Cui and Yu (2014) & $\mathrm{RR} / \mathrm{NRR}$ & MM & Cmax & DS \\
\hline Ghamginzadeh et al. (2014) & $\mathrm{RR} / \mathrm{NRR}$ & MM & MO & DS \\
\hline Gomes et al. (2014) & RR & DRD & MO & DS \\
\hline Hao et al. (2014) & RR & MM & $\mathrm{MO}$ & SS-PS \\
\hline Haouari et al. (2014) & RR & PRN & Cmax & DS \\
\hline Jeang (2014) & DRD & DRD & $\mathrm{MO}$ & SS \\
\hline Kadam and Kadam (2014) & RR & DRD & Cmax & DS \\
\hline Ke and Ma (2014) & DRD & $\mathrm{AC}$ & $\mathrm{CBO}$ & FS \\
\hline Li et al. (2014) & $\mathrm{RR}$ & DRD & RRO & SS \\
\hline Liu et al. (2014) & $\mathrm{RR} / \mathrm{NRR}$ & $\mathrm{MM}$ & Cmax & DS \\
\hline Menesi and Hegazy (2014) & RR & $\mathrm{MM}$ & $\mathrm{Cmax} / \mathrm{MO}$ & DS \\
\hline
\end{tabular}




\begin{tabular}{|c|c|c|c|c|}
\hline Article & Resource type & Activity characteristics & Objective function & $\begin{array}{l}\text { Cer- } \\
\text { tainty }\end{array}$ \\
\hline Messelis \& De Causmaecker (2014) & RR/NRR & $\overline{\mathrm{MM}}$ & Cmax & $\overline{\mathrm{DS}}$ \\
\hline Pérez et al. (2014) & $\mathrm{RR}$ & MM & MO & DS \\
\hline Qi et al. (2014) & RR & DRD & RRO & DS \\
\hline Rafiee et al. (2014) & $\mathrm{RR}$ & RV & NPV & SS \\
\hline Shirzadeh Chaleshtarti et al. (2014) & RR/NRR & DRD & Cmax & DS \\
\hline Tavana et al. (2014) & DRD & PRN/MM & MO & DS \\
\hline Vartouni and Khanli (2014) & RR/NRR & MM & Cmax & FS \\
\hline Wang et al. (2014a) & RR/NRR & MM & Cmax & DS \\
\hline Wang et al. (2014b) & RR/NRR & DRD & MO & PS \\
\hline Wuliang et al. (2014) & RR/NRR & MM & Cmax & DS \\
\hline Xiao et al. (2014) & $\mathrm{RR}$ & DRD & MO & DS \\
\hline Xiong et al. (2014) & $\mathrm{RR}$ & $\mathrm{AC}$ & MO & PS \\
\hline $\mathrm{Xu}$ and Feng (2014) & RR/NRR & $\mathrm{MM} / \mathrm{AC}$ & MO & FS \\
\hline Zhang (2014) & RR & DRD & MO & FS \\
\hline Aouni et al. (2015) & RR & DRD & MO & DS \\
\hline Ayodele et al. (2015) & RR/NRR & MM & Cmax & DS \\
\hline Azizoglu et al. (2015) & NRR & MM & Cmax & DS \\
\hline Beşikci et al. (2015) & RR/NRR & MM & TBO & DS \\
\hline Carlier and Moukrim (2015) & NRR/OR(Storage resources) & DRD & Cmax & DS \\
\hline Cheng et al. (2015) & $\mathrm{RR} / \mathrm{NRR}$ & $\mathrm{PRN} / \mathrm{MM} / \mathrm{RV}$ & TBO & DS \\
\hline Choi and Park (2015) & RR & $\mathrm{AC}$ & $\mathrm{CBO}$ & DS \\
\hline Creemers (2015) & $\mathrm{RR}$ & DRD & Cmax & SS \\
\hline Delgoshaei et al. (2015) & $\mathrm{RR}$ & PRN & Cmax & DS \\
\hline Gutjahr (2015) & RR & MM & $\mathrm{MO}$ & SS \\
\hline Kang and Choi (2015) & DRD & $\mathrm{AC}$ & $\mathrm{CBO}$ & SS \\
\hline Khalilzadeh (2015) & RR/NRR & MM & NPV & DS \\
\hline Knyazeva et al. (2015) & $\mathrm{RR}$ & DRD & Cmax & FS \\
\hline Lamas and Demeulemeester (2015) & RR & DRD & Cmax & PS \\
\hline Leyman and Vanhoucke (2015) & RR & DRD & NPV & DS \\
\hline Li and Womer (2015) & RR & DRD & Cmax & SS \\
\hline Liu et al. (2015) & RR & DRD & $\mathrm{CBO}$ & DS \\
\hline Ma et al. (2015) & RR & DRD & Cmax & SS \\
\hline Moukrim et al. (2015) & RR & PRN & Cmax & DS \\
\hline Ponz-Tienda et al. (2015) & RR & PRN & Cmax & FS \\
\hline Rajeev et al. (2015) & RR & DRD & TBO & DS \\
\hline Rezaeian et al. (2015) & $\mathrm{RR}$ & MM & MO & PS \\
\hline Salari et al. (2015) & DRD & MM & MO & FS \\
\hline Shahsavar et al. (2015) & $\mathrm{RR}$ & DRD & MO & DS \\
\hline Shou et al. (2015) & RR & PRN & Cmax & DS \\
\hline Song et al. (2015) & RR & DRD & $\mathrm{CBO}$ & DS \\
\hline Suresh et al. (2015) & $\mathrm{RR}$ & DRD & NPV & DS \\
\hline Toffolo et al. (2015) & RR/NRR(Local and global) & MM & Cmax & DS \\
\hline Vandenheede et al. (2015) & $\mathrm{RR}$ & RV & $\mathrm{CBO}$ & DS \\
\hline Xu et al. (2015) & DRD & MM & TBO/CBO(Profit) & FS \\
\hline Yuan et al. (2015) & $\mathrm{RR}$ & DRD & $\mathrm{CBO}$ & DS \\
\hline Afshar-Nadjafi (2016) & RR & DRD & TBO & PS \\
\hline Bianco et al. (2016) & RR & $\begin{array}{l}\text { OC(Variable execution } \\
\text { intensities) }\end{array}$ & RRO & DS \\
\hline Chakrabortty et al. (2016) & RR/NRR & MM & Cmax & RS \\
\hline Chen and Zhang (2016) & $\mathrm{RR}$ & PRN & $\mathrm{TBO} / \mathrm{Cmax} / \mathrm{OO}$ (Buffer) & FS \\
\hline Cheng et al. (2016) & RR & DRD & RRO & DS \\
\hline Delgoshaei et al. (2016) & RR & PRN/MM & NPV & DS \\
\hline Elbeltagi et al. (2016) & RR & MM & MO & DS \\
\hline Kreter et al. (2016) & RR & DRD & Cmax & DS \\
\hline Leyman and Vanhoucke (2016) & RR/NRR & MM & NPV & DS \\
\hline Maghsoudlou et al. (2016) & RR(Multi-skill) & MM & MO & DS \\
\hline Nikoofal Sahl Abadi et al. (2016) & $\mathrm{RR}$ & DRD & MO & DS \\
\hline Palacio and Larrea (2016) & $\mathrm{RR}$ & RV & MO & PS \\
\hline Schnell and Hartl (2016) & RR/NRR & MM & Cmax & DS \\
\hline Sebt et al. (2016) & RR/NRR & MM & Cmax & DS \\
\hline Suwa and Morita (2016) & $\mathrm{RR}$ & DRD & $\mathrm{CBO}$ (Revision cost) & RS \\
\hline
\end{tabular}




\begin{tabular}{lcccc}
\hline Article & Resource type & Activity characteristics & Objective function & $\begin{array}{c}\text { Cer- } \\
\text { tainty }\end{array}$ \\
\hline Tian et al. (2016) & RR & MM & Cmax & SS \\
Tran et al. (2016) & RR & RV & RRO & DS \\
Waligóra (2016) & RR & AC & NPV & DS \\
Xiao et al. (2016) & RR & DRD & MO & DS \\
Chakrabortty et al. (2017) & RR & DRD & Cmax & SS \\
Ghoddousi et al. (2017) & RR & DRD & MO & PS \\
Habibi et al. (2017) & RR & RV & MO & PS \\
Leyman and Vanhoucke (2017) & RR/OR(Cumulative resources) & DRD & NPV & DS \\
Rostami et al. (2017) & RR & DRD & Cmax & SS \\
Sebt et al. (2017) & RR/NRR & MM & Cmax & DS \\
Tritschler et al. (2017) & RR & DRD & DS \\
Zhu et al. (2017) & RR & DRD & RRO & DS \\
Zoraghi (2017) & RR/NRR & MM & DS \\
\hline Resource type (RR
\end{tabular}

Resource type: (RR: Renewable Resource || NRR: Non-renewable Resource ||| DCR: Doubly Constrained Resource ||| OR: Other Resource ||| DRD: Disregarded)

Activity characteristics: (PRN: Preemption || MM: Multi-mode || AC: Activity Crashing || RV: Resource Variation ||| OC: Other Characteristics || DRD: Disregarded)

Objective function: (Cmax: Project Completion time ||| TBO: Time-based Objectives (except Cmax) ||| NPV: Net Present Value ||| CBO: Cost-based Objectives (except NPV) || RRO: Renewable Resource Objective ||| NRRO: Non-renewable Resource Objective ||| MO: Multi-objective $\| \mid$ OO: Other Objectives)

Certainty: (DS: Deterministic Scheduling || RS: Reactive Scheduling ||| SS: Stochastic Scheduling ||FS: Fuzzy Scheduling ||| PS: Proactive Scheduling)

In Fig. 3, frequency of different RCPSP aspects is shown.

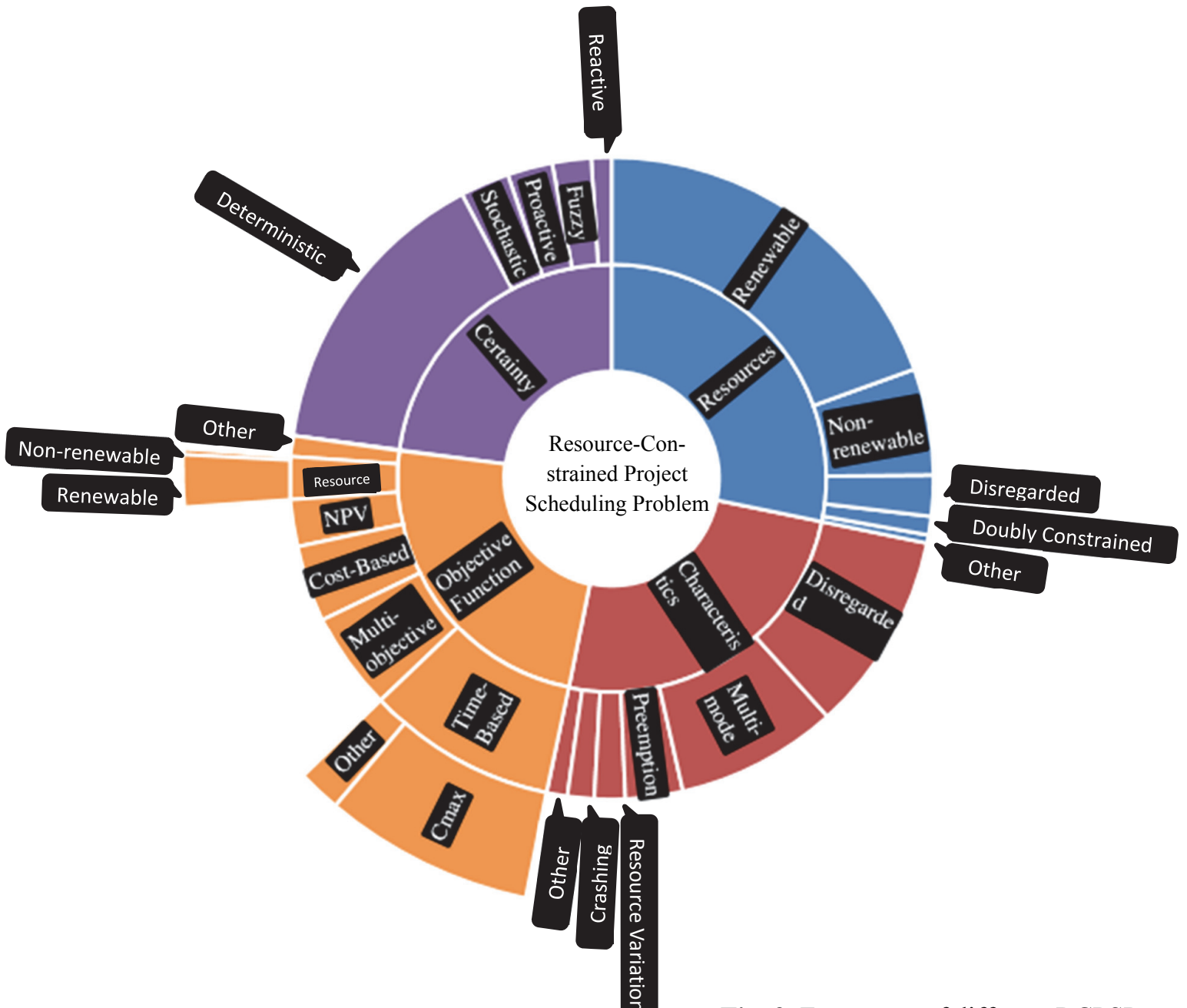

Fig. 3. Frequency of different RCPSP aspects 
In addition, the frequency percentage of each of the mentioned items are presented in Table 2.

Table 2

Frequency of each category

\begin{tabular}{|c|c|c|c|}
\hline \multicolumn{3}{|c|}{ Category } & \multirow{2}{*}{$\frac{\text { Frequency (\%) }}{69}$} \\
\hline \multirow{5}{*}{ Resource type } & Renewable & & \\
\hline & Non-renewable & & 19 \\
\hline & Doubly constrained & & 3 \\
\hline & Other & & 1 \\
\hline & Disregarded & & 7 \\
\hline \multirow{6}{*}{ Activity characteristics } & Preemption & & 12 \\
\hline & Multi-mode & & 33 \\
\hline & Crashing & & 5 \\
\hline & Resource variation & & 6 \\
\hline & Other & & 4 \\
\hline & Disregarded & & 40 \\
\hline \multirow{8}{*}{ Objective function } & \multirow{2}{*}{ Time-based } & Cmax & 33 \\
\hline & & Others & 7 \\
\hline & \multirow{2}{*}{ Cost-based } & Cost & 16 \\
\hline & & NPV & 10 \\
\hline & \multirow{2}{*}{ Resource-based } & Renewable resource & 8 \\
\hline & & Non-renewable resource & 1 \\
\hline & Multi-objective & & 21 \\
\hline & Other & & 4 \\
\hline \multirow{5}{*}{ Certainty } & Deterministic & & 66 \\
\hline & Reactive & & 5 \\
\hline & Stochastic & & 11 \\
\hline & Fuzzy & & 9 \\
\hline & Proactive & & 10 \\
\hline
\end{tabular}

According to the diagram of Fig. 3 and Table 2, it could be concluded that:

1. In terms of resources, it is observed that renewable resources have been used in most of the studies (about 69\%). Meanwhile, non-renewable and doubly constrained resources have been used in 19\% and $3 \%$ of the studies, respectively. Therefore, they can be invested in future studies. Moreover, there are other resources in addition to the mentioned resources, which can be considered in RCPSP studies. Some of these resources include energies (which are continuous inherently), specific human resources, including experts (where excessive use can lead to high costs), deteriorating resources, holding of which at project site can lead to corruption or reduction of their volume or turning obsolete, recycling resources, renting resources and even workplace and other new resources.

2. According to Fig. 3 and Table 2, characteristics such as multi-mode, preemption, resource variation, and crashing have played a role in 33,12, 6 and 5 percent of the evaluated RCPSP studies, respectively and they were neglected in $40 \%$ of these cases. Therefore, use of such characteristics, which are applicable and important both in practice and theory, increases the attractiveness of the problem and can enrich the implemented studies in the field of RCPSPs. In addition, other features, such as generalized precedence relationships, time-switch constraints and time-varying tasks can be applied in this category of problems.

3. Furthermore, while the parameters of RCPSPs are often changed under uncertainty condition and cause inefficiency of the basic scheduling timetable, the majority of evaluated problems in this field are presented under deterministic condition. In this regard, $66 \%$ of the evaluated articles investigated project scheduling problem under deterministic conditions and in 11, 10,9 and 5 percent of studies, stochastic, proactive, fuzzy and reactive approaches were used, respectively. Hence, application of uncertainty approaches can be regarded in future studies on RCPSPs due to adherence to real-world conditions. 
4. Moreover, time-based, cost-based, multi-objective and resource-based objectives were considered in 40, 26, 21 and 9 percent of the evaluated articles, where the objective of project completion time minimization was alone regarded in about one-third of the studies. Meanwhile, some objective functions, such as time-based objectives except Cmax minimization and objectives based on non-renewable resources are regarded as objectives that are less observed and can be used in future studies. As we know, today, multi-objective optimization is extremely taken into account due to responsiveness toward several objectives, simultaneously and meeting the needs of decision makers and, project scheduling problems are no exception. Therefore, the details of some studies related to multi-objective optimization of project scheduling problem are presented in Table 3.

\section{Table 3}

Comparison of the multi-objective project scheduling problems

\begin{tabular}{|c|c|c|c|c|c|c|c|c|}
\hline \multirow{2}{*}{ Article } & \multirow{2}{*}{$\begin{array}{c}\text { Number } \\
\text { of ob- } \\
\text { jectives }\end{array}$} & \multicolumn{2}{|c|}{$\begin{array}{c}\text { Time-based } \\
\text { objectives }\end{array}$} & \multicolumn{2}{|c|}{$\begin{array}{l}\text { Economic } \\
\text { objectives }\end{array}$} & \multicolumn{2}{|c|}{$\begin{array}{c}\text { Resource-based ob- } \\
\text { jectives }\end{array}$} & \multirow{2}{*}{ Others } \\
\hline & & Cmax & Other & Cost & NPV & $\begin{array}{c}\text { Renewa- } \\
\text { ble }\end{array}$ & $\begin{array}{l}\text { Non-re- } \\
\text { newable }\end{array}$ & \\
\hline Davis et al. (1992) & 2 & $\bar{\checkmark}$ & & & & $\checkmark$ & & \\
\hline Hapke and Slowinski (1993) & 3 & $\checkmark$ & $\checkmark$ & & & & & $\begin{array}{l}\text { Mean flow } \\
\text { time }\end{array}$ \\
\hline Hapke et al. (1994) & 2 & $\checkmark$ & $\checkmark$ & & & & & \\
\hline $\begin{array}{l}\text { Nudtasomboon and Randhawa } \\
\text { (1997) }\end{array}$ & 3 & $\checkmark$ & & $\checkmark$ & & $\checkmark$ & & \\
\hline Viana and de Sousa (2000) & 3 & $\checkmark$ & $\checkmark$ & & & $\checkmark$ & & \\
\hline Haouari and Al-Fawzan (2002) & 2 & $\checkmark$ & & & & & & Robustness \\
\hline Al-Fawzan and Haouari (2005) & 2 & $\checkmark$ & & & & & & Robustness \\
\hline Abbasi et al. (2006) & 2 & $\checkmark$ & & & & & & Robustness \\
\hline Kobylański and Kuchta (2007) & 2 & $\checkmark$ & & & & & & Robustness \\
\hline Heon Jun and El-Rayes (2011) & 2 & $\checkmark$ & & & & $\checkmark$ & & \\
\hline Xiong et al. (2011) & 3 & $\checkmark$ & & $\checkmark$ & & & & Robustness \\
\hline $\mathrm{Hu}$ and Flood (2012) & 2 & $\checkmark$ & & & & $\checkmark$ & & \\
\hline Vanucci et al. (2012) & 2 & $\checkmark$ & & $\checkmark$ & & & & \\
\hline Khalili et al. (2013) & 2 & $\checkmark$ & & & $\checkmark$ & & & \\
\hline Wang et al. (2013) & 2 & $\checkmark$ & & & & $\checkmark$ & & \\
\hline Abello and Michalewicz (2014) & 2 & $\checkmark$ & & & & $\checkmark$ & & \\
\hline Ghamginzadeh et al. (2014) & 2 & $\checkmark$ & & & $\checkmark$ & & & \\
\hline Gomes et al. (2014) & 2 & $\checkmark$ & & & & & & Robustness \\
\hline Jeang (2014) & 3 & $\checkmark$ & & $\checkmark$ & & & & Reliability \\
\hline Pérez et al. (2014) & 2 & & $\checkmark$ & & & & & $\begin{array}{l}\text { Constraints vio- } \\
\text { lations }\end{array}$ \\
\hline Wang et al. (2014b) & 4 & $\checkmark$ & & $\checkmark$ & & & & $\begin{array}{l}\text { Quality and Ro- } \\
\text { bustness }\end{array}$ \\
\hline Xiao et al. (2014) & 2 & $\checkmark$ & $\checkmark$ & & & & & \\
\hline Xiong et al. (2014) & 3 & $\checkmark$ & & $\checkmark$ & & & & Robustness \\
\hline Zhang (2014) & 2 & & $\checkmark$ & & & $\checkmark$ & & \\
\hline Aouni et al. (2015) & 3 & $\checkmark$ & & $\checkmark$ & & $\checkmark$ & & \\
\hline Gutjahr (2015) & 2 & $\checkmark$ & & $\checkmark$ & & & & \\
\hline Shahsavar et al. (2015) & 3 & $\checkmark$ & & $\checkmark$ & & $\checkmark$ & & \\
\hline Nikoofal Sahl Abadi et al. (2016) & 2 & $\checkmark$ & & & & $\checkmark$ & & \\
\hline Elbeltagi et al. (2016) & 4 & $\checkmark$ & & $\checkmark$ & $\checkmark$ & $\checkmark$ & & \\
\hline Maghsoudlou et al. (2016) & 3 & $\checkmark$ & & $\checkmark$ & & & & Quality \\
\hline Palacio and Larrea (2016) & 2 & $\checkmark$ & & & & & & Robustness \\
\hline Habibi et al. (2017) & 3 & $\checkmark$ & & & $\checkmark$ & & & Robustness \\
\hline
\end{tabular}

As can be seen, according to the Table 3, in most of the multi-objective project scheduling problems, cost-based objectives are considered along with time-based objectives and some objectives, such as NVP and objectives based on non-renewable resources are less used. Therefore, it is recommended that the newer objectives are used along with the main objectives (e.g., time and cost) to respond to the 
utility of project managers. Some of these objectives are quality, reliability and sustainable objectives (economic, environmental and social).

\section{Conclusion}

As mentioned earlier, today, Resource-Constrained Project Scheduling Problem (RCPSP) is significantly taken into account from two practical and theoretical aspects. Therefore, with regard to the huge volume of studies conducted in this area, it is necessary to summarize these articles. As a result, this paper was proposed to review the topics related to RCPSPs and evaluate the recent developments in this area and present the results for future studies. In this respect, first, the standard RCPSP was stated and then, the related developments were presented from four aspects of resources, characteristics of activities, type of objective function and availability level of information. Following that, details about 216 articles in the field of RCPSP during 1980-2017 have been summarized, and recommendations were made for future studies according to statistics obtained from the assessment of studies. Therefore, with regard to the mentioned notes about the research gaps and use of applicable assumptions in project scheduling researches, efficient and new studies can be obtained in this field.

\section{References}

Abbasi, B., Shadrokh, S., \& Arkat, J. (2006). Bi-objective resource-constrained project scheduling with robustness and makespan criteria. Applied mathematics and computation, 180(1), 146-152.

Abello, M. B., \& Michalewicz, Z. (2014). Multiobjective resource-constrained project scheduling with a time-varying number of tasks. The Scientific World Journal, 2014.

Abello, M. B., Michalewicz, Z., \& Bui, L. T. (2012, June). A reactive-proactive approach for solving dynamic scheduling with time-varying number of tasks. In 2012 IEEE Congress on Evolutionary Computation (pp. 1-10). IEEE.

Afruzi, E. N., Najafi, A. A., Roghanian, E., \& Mazinani, M. (2014). A Multi-Objective Imperialist Competitive Algorithm for solving discrete time, cost and quality trade-off problems with modeidentity and resource-constrained situations. Computers \& Operations Research, 50, 80-96.

Afshar-Nadjafi, B. (2014a). Multi-mode resource availability cost problem with recruitment and release dates for resources. Applied Mathematical Modelling, 38(21), 5347-5355.

Afshar-Nadjafi, B. (2014b). Resource Constrained Project Scheduling Subject to Due Dates: Preemption Permitted with Penalty. Advances in Operations Research, 2014.

Afshar-Nadjafi, B. (2016). A new proactive approach to construct a robust baseline schedule considering quality factor. International Journal of Industrial and Systems Engineering, 22(1), 63-72.

Afshar-Nadjafi, B., \& Majlesi, M. (2014). Resource constrained project scheduling problem with setup times after preemptive processes. Computers \& Chemical Engineering, 69, 16-25.

Agarwal, R., Tiwari, M. K., \& Mukherjee, S. K. (2007). Artificial immune system based approach for solving resource constraint project scheduling problem. The International Journal of Advanced Manufacturing Technology, 34(5-6), 584-593.

Ahn, T., \& Erenguc, S. S. (1998). The resource constrained project scheduling problem with multiple crashable modes: a heuristic procedure. European Journal of Operational Research, 107(2), 250259.

Akkan, C., Drexl, A., \& Kimms, A. (2005). Network decomposition-based benchmark results for the discrete time-cost tradeoff problem. European Journal of Operational Research, 165(2), 339-358.

Al-Fawzan, M. A., \& Haouari, M. (2005). A bi-objective model for robust resource-constrained project scheduling. International Journal of production economics, 96(2), 175-187.

Aouni, B., d'Avignon, G., \& Gagnon, M. (2015). Goal Programming for Multi-Objective ResourceConstrained Project Scheduling. In Handbook on Project Management and Scheduling Vol. 1 (pp. 429-442). Springer International Publishing. 
Atli, O., \& Kahraman, C. (2014). Resource-constrained project scheduling problem with multiple execution modes and fuzzy/crisp activity durations. Journal of Intelligent \& Fuzzy Systems, 26(4), 2001-2020.

Ayodele, M., McCall, J., \& Regnier-Coudert, O. (2015, July). Probabilistic Model Enhanced Genetic Algorithm for Multi-Mode Resource Constrained Project Scheduling Problem. In Proceedings of the Companion Publication of the 2015 Annual Conference on Genetic and Evolutionary Computation (pp. 745-746). ACM.

Azizoglu, M., Çetinkaya, F. C., \& Pamir, S. K. (2015). LP relaxation-based solution algorithms for the multi-mode project scheduling with a non-renewable resource. European Journal of Industrial Engineering, 9(4), 450-469.

Ballestín, F. (2007, April). A genetic algorithm for the resource renting problem with minimum and maximum time lags. In European Conference on Evolutionary Computation in Combinatorial Optimization (pp. 25-35). Springer Berlin Heidelberg.

Ballestín, F. (2008). Different codifications and metaheuristic algorithms for the resource renting problem with minimum and maximum time lags. In Recent Advances in Evolutionary Computation for Combinatorial Optimization (pp. 187-202). Springer Berlin Heidelberg.

Ballestin, F., \& Trautmann, N. (2008). An iterated-local-search heuristic for the resource-constrained weighted earliness-tardiness project scheduling problem. International Journal of Production Research, 46(22), 6231-6249.

Ballestín, F., Barrios, A., \& Valls, V. (2013). Looking for the best modes helps solving the MRCPSP/max. International Journal of Production Research, 51(3), 813-827.

Ballestín, F., Valls, V., \& Quintanilla, S. (2009). Scheduling projects with limited number of preemptions. Computers \& Operations Research, 36(11), 2913-2925.

Bartusch, M., Möhring, R. H., \& Radermacher, F. J. (1988). Scheduling project networks with resource constraints and time windows. Annals of operations Research, 16(1), 199-240.

Berthaut, F., Pellerin, R., Perrier, N., \& Hajji, A. (2014). Time-cost trade-offs in resource-constraint project scheduling problems with overlapping modes. International Journal of Project Organisation and Management, 6(3), 215-236.

Beşikci, U., Bilge, Ü., \& Ulusoy, G. (2015). Multi-mode resource constrained multi-project scheduling and resource portfolio problem. European Journal of Operational Research, 240(1), 22-31.

Bhaskar, T., Pal, M. N., \& Pal, A. K. (2011). A heuristic method for RCPSP with fuzzy activity times. European Journal of Operational Research, 208(1), 57-66.

Bianco, L., Caramia, M., \& Giordani, S. (2016). Resource levelling in project scheduling with generalized precedence relationships and variable execution intensities. OR Spectrum, 38(2), 405-425.

Bierwirth, C., \& Mattfeld, D. C. (1999). Production scheduling and rescheduling with genetic algorithms. Evolutionary computation, 7(1), 1-17.

Blazewicz, J., Lenstra, J. K., \& Kan, A. R. (1983). Scheduling subject to resource constraints: classification and complexity. Discrete Applied Mathematics, 5(1), 11-24.

Boctor, F. F. (1993). Heuristics for scheduling projects with resource restrictions and several resourceduration modes. The International Journal of Production Research, 31(11), 2547-2558.

Boctor, F. F. (1996). A new and efficient heuristic for scheduling projects with resource restrictions and multiple execution modes. European Journal of Operational Research, 90(2), 349-361.

Browning, T. R., \& Yassine, A. A. (2010). Resource-constrained multi-project scheduling: Priority rule performance revisited. International Journal of Production Economics, 126(2), 212-228.

Buddhakulsomsiri, J., \& Kim, D. S. (2006). Properties of multi-mode resource-constrained project scheduling problems with resource vacations and activity splitting. European Journal of Operational Research, 175(1), 279-295.

Buddhakulsomsiri, J., \& Kim, D. S. (2007). Priority rule-based heuristic for multi-mode resource-constrained project scheduling problems with resource vacations and activity splitting. European Journal of Operational Research, 178(2), 374-390.

Can, A., \& Ulusoy, G. (2014). Multi-project scheduling with two-stage decomposition. Annals of Operations Research, 217(1), 95-116. 
Čapek, R., Šůcha, P., \& Hanzálek, Z. (2012). Production scheduling with alternative process plans. European Journal of Operational Research, 217(2), 300-311.

Carlier, J., \& Moukrim, A. (2015). Storage Resources. In Handbook on Project Management and Scheduling Vol. 1 (pp. 177-189). Springer International Publishing.

Cavalcante, C. C., De Souza, C. C., Savelsbergh, M. W., Wang, Y., \& Wolsey, L. A. (2001). Scheduling projects with labor constraints. Discrete Applied Mathematics, 112(1), 27-52.

Chai, G., Huang, S., Zhang, G., \& Su, Y. (2010, August). Optimization of Bonus-Penalty Structure in Flexible Resources-Constrained Project Scheduling Problems from Both Sides of the Contract. In Business Intelligence and Financial Engineering (BIFE), 2010 Third International Conference on (pp. 109-113). IEEE.

Chakrabortty, R. K., Sarker, R. A., \& Essam, D. L. (2014, November). Event based approaches for solving multi-mode resource constraints project scheduling problem. In IFIP International Conference on Computer Information Systems and Industrial Management (pp. 375-386). Springer Berlin Heidelberg.

Chakrabortty, R. K., Sarker, R. A., \& Essam, D. L. (2016). Multi-mode resource constrained project scheduling under resource disruptions. Computers \& Chemical Engineering, 88, 13-29.

Chakrabortty, R. K., Sarker, R. A., \& Essam, D. L. (2017). Resource constrained project scheduling with uncertain activity durations. Computers \& Industrial Engineering.

Chanas, S., \& Kamburowski, J. (1981). The use of fuzzy variables in PERT. Fuzzy sets and systems, 5(1), 11-19.

Chen, A. H. L., Liang, Y. C., \& Padilla, J. D. (2014). An Entropy-Based Upper Bound Methodology for Robust Predictive Multi-Mode RCPSP Schedules. Entropy, 16(9), 5032-5067.

Chen, L., \& Zhang, Z. (2014). A Two-Stage Resource-Constrained Project Scheduling Model with Proactive and Reactive Strategies Under Uncertainty. In Proceedings of the Eighth International Conference on Management Science and Engineering Management (pp. 1397-1407). Springer Berlin Heidelberg.

Chen, L., \& Zhang, Z. (2016). Preemption resource-constrained project scheduling problems with fuzzy random duration and resource availabilities. Journal of Industrial and Production Engineering, 110.

Chen, W. N., \& Zhang, J. (2012). Scheduling multi-mode projects under uncertainty to optimize cash flows: a Monte Carlo ant colony system approach. Journal of computer science and technology, 27(5), 950-965.

Chen, W. N., Zhang, J., Liu, O., \& Liu, H. L. (2010, July). A Monte-Carlo ant colony system for scheduling multi-mode projects with uncertainties to optimize cash flows. In IEEE Congress on Evolutionary Computation (pp. 1-8). IEEE.

Cheng, J., Fowler, J., Kempf, K., \& Mason, S. (2015). Multi-mode resource-constrained project scheduling problems with non-preemptive activity splitting. Computers \& Operations Research, 53, $275-$ 287.

Cheng, M. Y., Tran, D. H., \& Hoang, N. D. (2016). Fuzzy clustering chaotic-based differential evolution for resource leveling in construction projects. Journal of Civil Engineering and Management, $1-12$.

Cheng, M. Y., Tran, D. H., \& Wu, Y. W. (2014). Using a fuzzy clustering chaotic-based differential evolution with serial method to solve resource-constrained project scheduling problems. Automation in Construction, 37, 88-97.

Choi, B. C., \& Park, M. J. (2015). A continuous time-cost tradeoff problem with multiple milestones and completely ordered jobs. European Journal of Operational Research, 244(3), 748-752.

Chtourou, H., \& Haouari, M. (2008). A two-stage-priority-rule-based algorithm for robust resourceconstrained project scheduling. Computers \& industrial engineering, 55(1), 183-194.

Church, L. K., \& Uzsoy, R. (1992). Analysis of periodic and event-driven rescheduling policies in dynamic shops. International Journal of Computer Integrated Manufacturing, 5(3), 153-163.

Colak, E., \& Azizoglu, M. (2014). A resource investment problem with time/resource trade-offs. Journal of the Operational Research Society, 65(5), 777-790. 
Creemers, S. (2014, December). The resource-constrained project scheduling problem with stochastic activity durations. In 2014 IEEE International Conference on Industrial Engineering and Engineering Management (pp. 453-457). IEEE.

Creemers, S. (2015). Minimizing the expected makespan of a project with stochastic activity durations under resource constraints. Journal of Scheduling, 18(3), 263-273.

Creemers, S., Leus, R., De Reyck, B., \& Lambrecht, M. (2008, December). Project scheduling for maximum NPV with variable activity durations and uncertain activity outcomes. In 2008 IEEE International Conference on Industrial Engineering and Engineering Management (pp. 183-187). IEEE.

Cui, J., \& Yu, L. (2014, December). An efficient discrete particle swarm optimization for solving multimode resource-constrained project scheduling problem. In 2014 IEEE International Conference on Industrial Engineering and Engineering Management (pp. 858-862). IEEE.

Damak, N., Jarboui, B., \& Loukil, T. (2013, May). Non-dominated Sorting Genetic Algorithm-II to solve bi-objective multi-mode resource-constrained project scheduling problem. In Control, Decision and Information Technologies (CoDIT), 2013 International Conference on (pp. 842-846). IEEE.

Damay, J., Quilliot, A., \& Sanlaville, E. (2007). Linear programming based algorithms for preemptive and non-preemptive RCPSP. European Journal of Operational Research, 182(3), 1012-1022.

Davis, K. R., Stam, A., \& Grzybowski, R. A. (1992). Resource constrained project scheduling with multiple objectives: A decision support approach. Computers \& operations research, 19(7), 657669.

De Reyck, B., \& Herroelen, W. (1999). The multi-mode resource-constrained project scheduling problem with generalized precedence relations. European Journal of Operational Research, 119(2), 538556.

Deblaere, F., Demeulemeester, E., \& Herroelen, W. (2011). Reactive scheduling in the multi-mode RCPSP. Computers \& Operations Research, 38(1), 63-74.

Delgoshaei, A., Al-Mudhafar, A., \& Ariffin, M. (2016). Developing a new method for modifying overallocated multi-mode resource constraint schedules in the presence of preemptive resources. Decision Science Letters, 5(4), 499-518.

Delgoshaei, A., Ariffin, M., Baharudin, B. H. T. B., \& Leman, Z. (2015). Minimizing makespan of a resource-constrained scheduling problem: A hybrid greedy and genetic algorithms. International Journal of Industrial Engineering Computations, 6(4), 503-520.

Demeulemeester, E. L., \& Herroelen, W. S. (1996). An efficient optimal solution procedure for the preemptive resource-constrained project scheduling problem. European Journal of Operational Research, 90(2), 334-348.

Demeulemeester, E., De Reyck, B., Foubert, B., Herroelen, W., \& Vanhoucke, A. M. (1998). New computational results on the discrete time/cost trade-off problem in project networks. Journal of the Operational Research Society, 49(11), 1153-1163.

Drexl, A., Nissen, R., Patterson, J. H., \& Salewski, F. (2000). ProGen/ $\pi$ x-An instance generator for resource-constrained project scheduling problems with partially renewable resources and further extensions. European Journal of Operational Research, 125(1), 59-72.

Drezet, L. E., \& Billaut, J. C. (2008). A project scheduling problem with labour constraints and timedependent activities requirements. International Journal of Production Economics, 112(1), 217225.

Elbeltagi, E., Ammar, M., Sanad, H., \& Kassab, M. (2016). Overall multiobjective optimization of construction projects scheduling using particle swarm. Engineering, Construction and Architectural Management, 23(3), 265-282.

Elmaghraby, S. E. (1977). Activity networks: Project planning and control by network models. John Wiley \& Sons.

Fallah, M., Aryanezhad, M. B., \& Ashtiani, B. (2010, December). Preemptive resource constrained project scheduling problem with uncertain resource availabilities: Investigate worth of proactive 
strategies. In Industrial Engineering and Engineering Management (IEEM), 2010 IEEE International Conference on (pp. 646-650). IEEE.

Fink, A., \& Homberger, J. (2013). An ant-based coordination mechanism for resource-constrained project scheduling with multiple agents and cash flow objectives. Flexible Services and Manufacturing Journal, 25(1-2), 94-121.

Ghamginzadeh, A., Najafi, A. A., \& Azimia, P. (2014). Solving a multi-objective resource-constrained project scheduling problem using a cuckoo optimization algorithm. Scientia Iranica. Transaction E, Industrial Engineering, 21(6), 2419.

Ghoddousi, P., Ansari, R., \& Makui, A. (2017). An improved robust buffer allocation method for the project scheduling problem. Engineering Optimization, 49(4), 718-731.

Göçken, T. (2013). Solution of fuzzy multi-objective project crashing problem. Neural Computing and Applications, 23(7-8), 2167-2175.

Goldratt, E. M. (1997). Critical chain: A business novel. Great Barrington, MA: North River Press.

Golenko-Ginzburg, D., Gonik, A., \& Baron, A. (2006). Resource Constrained Project Scheduling Models under Random Disturbances. In Perspectives in Modern Project Scheduling (pp. 53-78). Springer US.

Gomes, H. C., das Neves, F. D. A., \& Souza, M. J. F. (2014). Multi-objective metaheuristic algorithms for the resource-constrained project scheduling problem with precedence relations. Computers \& Operations Research, 44, 92-104.

Gourgand, M., Kemmoe Tchomte, S., \& Quilliot, A. (2008). Modelling and solving a multimode and multisite industrial problem: Lagrangean relaxation and heuristic approaches. European Journal of Industrial Engineering, 2(2), 190-206.

Gutjahr, W. J. (2015). Bi-Objective Multi-Mode Project Scheduling Under Risk Aversion. European Journal of Operational Research, 246(2), 421-434.

Habibi, F., Barzinpour, F., Sadjadi, S. (2017). A Multi-objective optimization model for project scheduling with time-varying resource requirements and capacities. Journal of Industrial and Systems Engineering, 10(special issue on scheduling), 92-118.

Hao, X., Lin, L., \& Gen, M. (2014). An effective multi-objective EDA for robust resource constrained project scheduling with uncertain durations. Procedia Computer Science, 36, 571-578.

Haouari, M., \& Al-Fawzan, M. A. (2002). A bi-objective model for maximizing the quality in project scheduling (Vol. 14). DIMACS technical report 2002.

Haouari, M., Kooli, A., Néron, E., \& Carlier, J. (2014). A preemptive bound for the resource constrained project scheduling problem. Journal of Scheduling, 17(3), 237-248.

Hapke, M., \& Slowinski, R. (1993). A DSS for Ressource - Constrained Project Scheduling under Uncertainty. Journal of Decision Systems, 2(2), 111-128.

Hapke, M., Jaszkiewicz, A., \& Slowinski, R. (1994). Fuzzy project scheduling system for software development. Fuzzy Sets and Systems, 67(1), 101-117.

Hapke, M., Jaszkiewicz, A., \& Słowiński, R. (1998). Interactive analysis of multiple-criteria project scheduling problems. European Journal of Operational Research, 107(2), 315-324.

Hartmann, S. (2013). Project scheduling with resource capacities and requests varying with time: a case study. Flexible Services and Manufacturing Journal, 25(1-2), 74-93.

Hartmann, S., \& Briskorn, D. (2010). A survey of variants and extensions of the resource-constrained project scheduling problem. European Journal of operational research, 207(1), 1-14.

Heon Jun, D., \& El-Rayes, K. (2011). Multiobjective optimization of resource leveling and allocation during construction scheduling. Journal of Construction Engineering and Management, 137(12), 1080-1088.

Herroelen, W., \& Leus, R. (2005). Project scheduling under uncertainty: Survey and research potentials. European journal of operational research, 165(2), 289-306.

Hsu, C. C., \& Kim, D. S. (2005). A new heuristic for the multi-mode resource investment problem. Journal of the Operational Research Society, 56(4), 406-413. 
Hu, J., \& Flood, I. (2012). A multi-objective scheduling model for solving the resource-constrained project scheduling and resource leveling problems. In Interntional Conference on Computing in Civil Engineering (pp. 49-56).

Huang, W., \& Ding, L. (2011). Project-scheduling problem with random time-dependent activity duration times. IEEE Transactions on Engineering Management, 58(2), 377-387.

Huang, W., Oh, S. K., \& Pedrycz, W. (2013). A fuzzy time-dependent project scheduling problem. Information Sciences, 246, 100-114.

Janczura, M. A. R. E. K., \& Kuchta, D. O. R. O. T. A. (2012). Proactive and reactive scheduling with fuzzy activity times. World Scientific Proc. Series on Computer Engineering and Information Science, $7,495$.

Jeang, A. (2014). Project management for uncertainty with multiple objectives optimisation of time, cost and reliability. International Journal of Production Research, 53(5), 1503-1526.

Jing-wen, Z., \& Hui-fang, S. (2010, November). Multi-resource constrained discrete time/cost tradeoff problem and its improved genetic algorithm. In Management Science and Engineering (ICMSE), 2010 International Conference on (pp. 123-128). IEEE.

Kadam, S. U., \& Kadam, N. S. (2014, January). Solving resource-constrained project scheduling problem by genetic algorithm. In Business and Information Management (ICBIM), 2014 2nd International Conference on(pp. 159-164). IEEE.

Kadrou, Y., \& Najid, N. M. (2006, October). A new heuristic to solve RCPSP with multiple execution modes and multi-skilled labor. In Computational Engineering in Systems Applications, IMACS Multiconference on (Vol. 2, pp. 1302-1309). IEEE.

Kanagasabapathi, B., Rajendran, C., \& Ananthanarayanan, K. (2010). Scheduling in resource-constrained multiple projects to minimise the weighted tardiness and weighted earliness of projects. International Journal of Operational Research, 7(3), 334-386.

Kang, C., \& Choi, B. C. (2015). An adaptive crashing policy for stochastic time-cost tradeoff problems. Computers \& Operations Research, 63, 1-6.

Kaplan, LA (1988). Resource-constrained project scheduling with pre-emption of jobs. Unpublished Ph.D. dissertation, University of Michigan, Ann Arbor.

Karshenas, S., \& Haber, D. (1990). Economic optimization of construction project scheduling. Construction Management and Economics, 8(2), 135-146.

Ke, H., \& Liu, B. (2005). Project scheduling problem with stochastic activity duration times. Applied Mathematics and Computation, 168(1), 342-353.

Ke, H., \& Ma, J. (2014). Modeling project time-cost trade-off in fuzzy random environment. Applied Soft Computing, 19, 80-85.

Khalili, S., Najafi, A. A., \& Niaki, S. T. A. (2013). Bi-objective resource constrained project scheduling problem with makespan and net present value criteria: two meta-heuristic algorithms. The International Journal of Advanced Manufacturing Technology, 69(1-4), 617-626.

Khalilzadeh, M. (2015). A honey bee swarm optimization algorithm for minimizing the total costs of resources in MRCPSP. Indian Journal of Science and Technology, 8(11).

Khalilzadeh, M., Kianfar, F., Shirzadeh Chaleshtari, A., Shadrokh, S., \& Ranjbar, M. (2012). A modified PSO algorithm for minimizing the total costs of resources in MRCPSP. Mathematical Problems in Engineering, 2012.

Khemakhem, M. A., \& Chtourou, H. (2013). Efficient robustness measures for the resource-constrained project scheduling problem. International Journal of Industrial and Systems Engineering, 14(2), 245-267.

Khoshjahan, Y., Najafi, A. A., \& Afshar-Nadjafi, B. (2013). Resource constrained project scheduling problem with discounted earliness-tardiness penalties: Mathematical modeling and solving procedure. Computers \& Industrial Engineering, 66(2), 293-300.

Klerides, E., \& Hadjiconstantinou, E. (2010). A decomposition-based stochastic programming approach for the project scheduling problem under time/cost trade-off settings and uncertain durations. Computers \& Operations Research, 37(12), 2131-2140. 
Knyazeva, M., Bozhenyuk, A., \& Rozenberg, I. (2015). Resource-constrained Project Scheduling Approach Under Fuzzy Conditions. Procedia Computer Science, 77, 56-64.

Kogan, K., \& Khmelnitsky, E. (1998). Tracking demands in optimal control of managerial systems with continuously-divisible, doubly constrained resources. Journal of Global Optimization, 13(1), 43-59.

Konstantinidis, P. D. (1998). A model to optimize project resource allocation by construction of a balanced histogram. European journal of operational research, 104(3), 559-571.

Kreter, S., Rieck, J., \& Zimmermann, J. (2016). Models and solution procedures for the resource-constrained project scheduling problem with general temporal constraints and calendars. European Journal of Operational Research, 251(2), 387-403.

Kyriakidis, T. S., Kopanos, G. M., \& Georgiadis, M. C. (2012). MILP formulations for single-and multi-mode resource-constrained project scheduling problems. Computers \& Chemical Engineering, 36, 369-385.

Lamas, P., \& Demeulemeester, E. (2015). A purely proactive scheduling procedure for the resourceconstrained project scheduling problem with stochastic activity durations. Journal of Scheduling, 120.

Lambrechts, O., Demeulemeester, E., \& Herroelen, W. (2008). Proactive and reactive strategies for resource-constrained project scheduling with uncertain resource availabilities. Journal of scheduling, 11(2), 121-136.

Lambrechts, O., Demeulemeester, E., \& Herroelen, W. (2011). Time slack-based techniques for robust project scheduling subject to resource uncertainty. Annals of Operations Research, 186(1), 443-464.

Leyman, P., \& Vanhoucke, M. (2015). A new scheduling technique for the resource-constrained project scheduling problem with discounted cash flows. International Journal of Production Research, 53(9), 2771-2786.

Leyman, P., \& Vanhoucke, M. (2016). Payment models and net present value optimization for resource-constrained project scheduling. Computers \& Industrial Engineering, 91, 139-153.

Leyman, P., \& Vanhoucke, M. (2017). Capital-and resource-constrained project scheduling with net present value optimization. European Journal of Operational Research, 256(3), 757-776.

Li, F., Lai, C., \& Shou, Y. (2011, December). Particle swarm optimization for preemptive project scheduling with resource constraints. In Industrial Engineering and Engineering Management (IEEM), 2011 IEEE International Conference on (pp. 869-873). IEEE.

Li, H., \& Womer, N. K. (2015). Solving stochastic resource-constrained project scheduling problems by closed-loop approximate dynamic programming. European Journal of Operational Research, 246(1), 20-33.

Li, H., \& Zhang, H. (2013). Ant colony optimization-based multi-mode scheduling under renewable and nonrenewable resource constraints. Automation in Construction, 35, 431-438.

Li, H., Xu, Z., \& Demeulemeester, E. (2014). Scheduling policies for the stochastic resource leveling problem. Journal of Construction Engineering and Management, 141(2), 04014072.

Li, Z., Wuliang, P., \& Zhongliang, Z. (2010, May). An ant colony system for solving resource leveling problem. In Intelligent Computation Technology and Automation (ICICTA), 2010 International Conference on (Vol. 1, pp. 489-492). IEEE.

Liu, M., Liu, J., Wimmers, M. O., \& Zhou, M. (2015). A differential evolution algorithm for resource investment problem with tardiness. In 2015 IEEE Congress on Evolutionary Computation (CEC) (pp. 346-352). IEEE.

Liu, S., Chen, D., \& Wang, Y. (2014). Memetic algorithm for multi-mode resource-constrained project scheduling problems. Journal of Systems Engineering and Electronics, 25(4), 609-617.

Liu, Z., \& Zheng, Y. (2008, July). Resource-constrained multiple projects scheduling with the objective of minimizing activities cost. In 2008 Chinese Control and Decision Conference (pp. 1027-1032). IEEE.

Ma, W., Che, Y., Huang, H., \& Ke, H. (2015). Resource-constrained project scheduling problem with uncertain durations and renewable resources. International Journal of Machine Learning and Cybernetics, 1-9. 
Maghsoudlou, H., Afshar-Nadjafi, B., \& Niaki, S. T. A. (2016). A multi-objective invasive weeds optimization algorithm for solving multi-skill multi-mode resource constrained project scheduling problem. Computers \& Chemical Engineering, 88, 157-169.

Maniezzo, V., \& Mingozzi, A. (1999). The project scheduling problem with irregular starting time costs. Operations Research Letters, 25(4), 175-182.

Menesi, W., \& Hegazy, T. (2014). Multimode resource-constrained scheduling and leveling for practical-size projects. Journal of management in engineering, 31(6), 04014092.

Messelis, T., \& De Causmaecker, P. (2014). An automatic algorithm selection approach for the multimode resource-constrained project scheduling problem. European Journal of Operational Research, 233(3), 511-528.

Möhring, R. H. (1984). Minimizing costs of resource requirements in project networks subject to a fixed completion time. Operations Research, 32(1), 89-120.

Möhring, R. H., Schulz, A. S., Stork, F., \& Uetz, M. (2001). On project scheduling with irregular starting time costs. Operations Research Letters, 28(4), 149-154.

Möhring, R. H., Schulz, A. S., Stork, F., \& Uetz, M. (2003). Solving project scheduling problems by minimum cut computations. Management Science, 49(3), 330-350.

Montoya-Torres, J. R., Solano-Charris, E. L., \& Duran-Cantor, C. (2012). MEMETIC ALGORITHM TO MINIMIZE COSTS OF ACTIVITIES IN RCPSP. Dyna, 79(174), 86-95.

Moukrim, A., Quilliot, A., \& Toussaint, H. (2015). An effective branch-and-price algorithm for the Preemptive Resource Constrained Project Scheduling Problem based on minimal Interval Order Enumeration. European Journal of Operational Research, 244(2), 360-368.

Nabrzyski, J., \& Weglarz, J. (1997, September). On an expert system with multicriteria tabu search for multiobjective project scheduling. In Emerging Technologies and Factory Automation Proceedings, 1997. ETFA'97., 1997 6th International Conference on (pp. 287-291). IEEE.

Najafi, A. A., \& Azimi, F. (2009). A priority rule-based heuristic for resource investment project scheduling problem with discounted cash flows and tardiness penalties. Mathematical Problems in Engineering, 2009.

Najafi, A. A., \& Niaki, S. T. A. (2005). Resource investment problem with discounted cash flows. $I N-$ TERNATIONAL JOURNAL OF ENGINEERING-MATERIALS AND ENERGY RESEARCH CENTER-, 18(1), 53.

Najafi, A. A., \& Niaki, S. T. A. (2006). A genetic algorithm for resource investment problem with discounted cash flows. Applied Mathematics and Computation, 183(2), 1057-1070.

Najafi, A. A., Niaki, S. T. A., \& Shahsavar, M. (2009). A parameter-tuned genetic algorithm for the resource investment problem with discounted cash flows and generalized precedence relations. Computers \& Operations Research, 36(11), 2994-3001.

Najafi, A. A., Zoraghi, N., \& Azimi, F. (2011). Scheduling a project to minimize costs of material requirements. World Academy of Science, Engineering and Technology, 78, 134-137.

Neumann, K., \& Zimmermann, J. (1999). Resource levelling for projects with schedule-dependent time windows. European Journal of Operational Research, 117(3), 591-605.

Neumann, K., \& Zimmermann, J. (2000). Procedures for resource leveling and net present value problems in project scheduling with general temporal and resource constraints. European Journal of Operational Research, 127(2), 425-443.

Neumann, K., Schwindt, C., \& Zimmermann, J. (2002). Recent results on resource-constrained project scheduling with time windows: Models, solution methods, and applications. Inst. für Wirtschaftstheorie und Operations-Research.

Nikoofal Sahl Abadi, N., Bagheri, M., \& Assadi, M. (2016). Multiobjective model for solving resourceleveling problem with discounted cash flows. International Transactions in Operational Research.

Nonobe, K., \& Ibaraki, T. (2006). A metaheuristic approach to the resource constrained project scheduling with variable activity durations and convex cost functions. In Perspectives in Modern Project Scheduling (pp. 225-248). Springer US.

Nübel, H. (2001). The resource renting problem subject to temporal constraints. OR-Spektrum, 23(3), 359-381. 
Nudtasomboon, N., \& Randhawa, S. U. (1997). Resource-constrained project scheduling with renewable and non-renewable resources and time-resource tradeoffs. Computers \& Industrial Engineering, 32(1), 227-242.

Palacio, J. D., \& Larrea, O. L. (2016). A lexicographic approach to the robust resource-constrained project scheduling problem. International Transactions in Operational Research.

Pérez, Á., Quintanilla, S., Lino, P., \& Valls, V. (2014). A multi-objective approach for a project scheduling problem with due dates and temporal constraints infeasibilities. International Journal of Production Research,52(13), 3950-3965.

Poder, E., Beldiceanu, N., \& Sanlaville, E. (2004). Computing a lower approximation of the compulsory part of a task with varying duration and varying resource consumption. European Journal of Operational Research, 153(1), 239-254.

Ponz-Tienda, J. L., Pellicer, E., Benlloch-Marco, J., \& Andrés-Romano, C. (2015). The Fuzzy Project Scheduling Problem with Minimal Generalized Precedence Relations. Computer-Aided Civil and Infrastructure Engineering,30(11), 872-891.

Prade, H. (1979). Using fuzzy set theory in a scheduling problem: a case study. Fuzzy sets and systems, 2(2), 153-165.

Proon, S., \& Jin, M. (2011). A genetic algorithm with neighborhood search for the resource-constrained project scheduling problem. Naval Research Logistics (NRL), 58(2), 73-82.

Qi, J., Guo, B., Lei, H., \& Zhang, T. (2014). Solving resource availability cost problem in project scheduling by pseudo particle swarm optimization. Journal of Systems Engineering and Electronics, 25(1), 69-76.

Rafiee, M., Kianfar, F., \& Farhadkhani, M. (2014). A multistage stochastic programming approach in project selection and scheduling. The International Journal of Advanced Manufacturing Technology, 70(9-12), 2125-2137.

Rajeev, S., Kurian, S., \& Paul, B. (2015). A modified serial scheduling scheme for resource constrained project scheduling weighted earliness tardiness problem. International Journal of Information and Decision Sciences, 7(3), 241-254.

Ranjbar, M., Hosseinabadi, S., \& Abasian, F. (2013). Minimizing total weighted late work in the resource-constrained project scheduling problem. Applied Mathematical Modelling, 37(23), 97769785.

Ranjbar, M., Khalilzadeh, M., Kianfar, F., \& Etminani, K. (2012). An optimal procedure for minimizing total weighted resource tardiness penalty costs in the resource-constrained project scheduling problem. Computers \& Industrial Engineering, 62(1), 264-270.

Rezaeian, J., Soleimani, F., Mohaselafshary, S., \& Arab, A. (2015). Using a meta-heuristic algorithm for solving the multi-mode resource-constrained project scheduling problem. International Journal of Operational Research, 24(1), 1-16.

Rostami, S., Creemers, S., \& Leus, R. (2017). New strategies for stochastic resource-constrained project scheduling. Journal of Scheduling, 1-17.

Russell, A. H. (1970). Cash flows in networks. Management Science, 16(5), 357-373.

Sadeh, N., Otsuka, S., \& Schnelbach, R. (1993, August). Predictive and reactive scheduling with the Micro-Boss production scheduling and control system. In Proceedings, IJCAI-93 Workshop on Knowledge-Based Production Planning, Scheduling and Control.

Salari, M., Bagherpour, M., \& Reihani, M. H. (2015). A time-cost trade-off model by incorporating fuzzy earned value management: A statistical based approach. Journal of Intelligent \& Fuzzy Systems, 28(4), 1909-1919.

Santos, M. A., \& Tereso, A. P. (2011). On the Multi-mode, Multi-skill Resource Constrained Project Scheduling Problem-A Software Application. In Soft computing in industrial applications (pp. 239248). Springer Berlin Heidelberg.

Schnell, A., \& Hartl, R. F. (2015). On the efficient modeling and solution of the multi-mode resourceconstrained project scheduling problem with generalized precedence relations. OR Spectrum, 38(2), 283-303. 
Sebt, M. H., Afshar, M. R., \& Alipouri, Y. (2016). Hybridization of genetic algorithm and fully informed particle swarm for solving the multi-mode resource-constrained project scheduling problem. Engineering Optimization, 1-18.

Sebt, M. H., Afshar, M. R., \& Alipouri, Y. (2017). Hybridization of genetic algorithm and fully informed particle swarm for solving the multi-mode resource-constrained project scheduling problem. Engineering Optimization, 49(3), 513-530.

Shadrokh, S. (2010). The preemptive resource-constrained project scheduling problem subject to due dates and preemption penalties: An integer programming approach. Journal of Optimization in Industrial Engineering, 35-39.

Shadrokh, S., \& Kianfar, F. (2005). A genetic algorithm for resource investment problems, enhanced by the revised Akpan method. Scientia Iranica, 12(1), 90-98.

Shadrokh, S., \& Kianfar, F. (2007). A genetic algorithm for resource investment project scheduling problem, tardiness permitted with penalty. European Journal of Operational Research, 181(1), 86101.

Shahsavar, A., Najafi, A. A., \& Niaki, S. T. A. (2015). Three self-adaptive multi-objective evolutionary algorithms for a triple-objective project scheduling problem. Computers \& Industrial Engineering, 87, 4-15.

Shavandi, H., Najafi, A. A., \& Moslehirad, A. (2012). Fuzzy project scheduling with discounted cash flows. ECONOMIC COMPUTATION AND ECONOMIC CYBERNETICS STUDIES AND RESEARCH, 46(1), 219-232.

Shi, Y. J., Qu, F. Z., Chen, W., \& Li, B. (2010). An artificial bee colony with random key for resourceconstrained project scheduling. In Life system modeling and intelligent computing (pp. 148-157). Springer Berlin Heidelberg.

Shirzadeh Chaleshtarti, A., Shadrokh, S., \& Fathi, Y. (2014). Branch and bound algorithms for resource constrained project scheduling problem subject to nonrenewable resources with prescheduled procurement. Mathematical Problems in Engineering, 2014.

Shou, Y., Li, Y., \& Lai, C. (2015). Hybrid particle swarm optimization for preemptive resource-constrained project scheduling. Neurocomputing, 148, 122-128.

Shukla, S. K., Son, Y. J., \& Tiwari, M. K. (2008). Fuzzy-based adaptive sample-sort simulated annealing for resource-constrained project scheduling. The International Journal of Advanced Manufacturing Technology, 36(9-10), 982-995.

Słowiński, R. (1980). Two approaches to problems of resource allocation among project activities-a comparative study. Journal of the Operational Research Society, 31(8), 711-723.

Słowinski, R. (1981). Multiobjective network scheduling with efficient use of renewable and nonrenewable resources. European Journal of Operational Research, 7(3), 265-273.

Smith, S. F. (1995). Reactive scheduling systems. In Intelligent scheduling systems (pp. 155-192). Springer US.

Sobel, M. J., Szmerekovsky, J. G., \& Tilson, V. (2009). Scheduling projects with stochastic activity duration to maximize expected net present value. European Journal of Operational Research, 198(3), 697-705.

Song, Y., Liu, J., Wimmers, M. O., \& Jiang, Z. (2015, May). A differential evolution algorithm with local search for resource investment project scheduling problems. In 2015 IEEE Congress on Evolutionary Computation (CEC) (pp. 1725-1731). IEEE.

Sung, C. S., \& Lim, S. K. (1997). A scheduling procedure for a general class of resource-constrained projects. Computers \& industrial engineering, 32(1), 9-17.

Suresh, M., Dutta, P., \& Jain, K. (2015). Resource Constrained Multi-Project Scheduling Problem with Resource Transfer Times. Asia-Pacific Journal of Operational Research, 32(06), 1550048.

Suwa, H. \& Morita, D. (2016). Reactive project scheduling method to enhance project progress under uncertainty. Journal of Advanced Mechanical Design, Systems, and Manufacturing, 10(3), JAMDSM0051-JAMDSM0051. 
Tavana, M., Abtahi, A. R., \& Khalili-Damghani, K. (2014). A new multi-objective multi-mode model for solving preemptive time-cost-quality trade-off project scheduling problems. Expert Systems with Applications, 41(4), 1830-1846.

Tian, W., Xu, J., \& Fu, Z. (2016). On the choice of baseline schedules for the discrete time/resource trade-off problem under stochastic environment. Journal of Difference Equations and Applications, $1-11$.

Toffolo, T. A., Santos, H. G., Carvalho, M. A., \& Soares, J. A. (2015). An integer programming approach to the multimode resource-constrained multiproject scheduling problem. Journal of Scheduling, 1-13.

Tran, D. H., Cheng, M. Y., \& Pham, A. D. (2016). Using Fuzzy Clustering Chaotic-based Differential Evolution to solve multiple resources leveling in the multiple projects scheduling problem. Alexandria Engineering Journal.

Tritschler, M., Naber, A., \& Kolisch, R. (2017). A hybrid metaheuristic for resource-constrained project scheduling with flexible resource profiles. European Journal of Operational Research, 262(1), 262273.

Ulusoy, G., \& Özdamar, L. (1996). A framework for an interactive project scheduling system under limited resources. European Journal of Operational Research, 90(2), 362-375.

Ulusoy, G., Sivrikaya-Şerifoğlu, F., \& Şahin, Ş. (2001). Four payment models for the multi-mode resource constrained project scheduling problem with discounted cash flows. Annals of Operations Research, 102(1-4), 237-261.

Valls, V., Laguna, M., Lino, P., Pérez, A., \& Quintanilla, S. (1999). Project scheduling with stochastic activity interruptions. In Project scheduling (pp. 333-353). Springer US.

Van de Vonder, S., Ballestin, F., Demeulemeester, E., \& Herroelen, W. (2007a). Heuristic procedures for reactive project scheduling. Computers \& Industrial Engineering, 52(1), 11-28.

Van De Vonder, S., Demeulemeester, E., \& Herroelen, W. (2005). Heuristic procedures for generating stable project baseline schedules. Available at SSRN 875289.

Van de Vonder, S., Demeulemeester, E., \& Herroelen, W. (2007b). A classification of predictive-reactive project scheduling procedures. Journal of Scheduling, 10(3), 195-207.

Van de Vonder, S., Demeulemeester, E., Herroelen, W., \& Leus, R. (2006a). The trade-off between stability and makespan in resource-constrained project scheduling. International Journal of Production Research, 44(2), 215-236.

Van de Vonder, S., Demeulemeester, E., Leus, R., \& Herroelen, W. (2006b). Proactive-reactive project scheduling trade-offs and procedures. In Perspectives in Modern Project Scheduling (pp. 25-51). Springer US.

Van Peteghem, V., \& Vanhoucke, M. (2010). A genetic algorithm for the preemptive and non-preemptive multi-mode resource-constrained project scheduling problem. European Journal of Operational Research, 201(2), 409-418.

Vandenheede, L., Vanhoucke, M., \& Maenhout, B. (2015). A scatter search for the extended resource renting problem. International Journal of Production Research, 1-21.

Vanhoucke, M., \& Debels, D. (2008). The impact of various activity assumptions on the lead time and resource utilization of resource-constrained projects. Computers \& Industrial Engineering, 54(1), 140-154.

Vanhoucke, M., Demeulemeester, E., \& Herroelen, W. (2002). Discrete time/cost trade-offs in project scheduling with time-switch constraints. Journal of the Operational Research Society, 53(7), 741751.

Vanucci, S. C., Carrano, E. G., Bicalho, R., \& Takahashi, R. H. (2012, June). A modified NSGA-II for the Multiobjective Multi-mode Resource-Constrained Project Scheduling Problem. In 2012 IEEE Congress on Evolutionary Computation (pp. 1-7). IEEE.

Vartouni, A. M., \& Khanli, L. M. (2014). A hybrid genetic algorithm and fuzzy set applied to multimode resource-constrained project scheduling problem. Journal of Intelligent \& Fuzzy Systems, 26(3), 1103-1112. 
Viana, A., \& de Sousa, J. P. (2000). Using metaheuristics in multiobjective resource constrained project scheduling. European Journal of Operational Research, 120(2), 359-374.

Vieira, G. E., Herrmann, J. W., \& Lin, E. (2000). Analytical models to predict the performance of a single-machine system under periodic and event-driven rescheduling strategies. International journal of production research, 38(8), 1899-1915.

Waligóra, G. (2016). Comparative Analysis of Some Metaheuristics for Discrete-Continuous Project Scheduling with Activities of Identical Processing Rates. Asia-Pacific Journal of Operational Research, 1650015.

Wang, K. S., Chi, J. H., \& Wan, E. H. (1993). Decision making of project under fuzzy information. Journal of the Chinese Institute of Engineers, 16(4), 533-541.

Wang, L., Fang, C., Mu, C. D., \& Liu, M. (2013). A Pareto-archived estimation-of-distribution algorithm for multiobjective resource-constrained project scheduling problem. IEEE Transactions on Engineering Management, 60(3), 617-626.

Wang, L., Ip, W. H., \& Lee, C. K. (2008, July). Resource constrained project scheduling of construction engineering with genetic algorithm. In 2008 Chinese Control and Decision Conference (pp. 14661470). IEEE.

Wang, L., Liu, J., \& Zhou, M. (2014a). An Organizational Cooperative Coevolutionary Algorithm for Multimode Resource-Constrained Project Scheduling Problems. In Asia-Pacific Conference on Simulated Evolution and Learning (pp. 680-690). Springer International Publishing.

Wang, W. X., Wang, X., Ge, X. L., \& Deng, L. (2014b). Multi-objective optimization model for multiproject scheduling on critical chain. Advances in Engineering Software, 68, 33-39.

Wiesemann, W., Kuhn, D., \& Rustem, B. (2010). Maximizing the net present value of a project under uncertainty. European Journal of Operational Research, 202(2), 356-367.

Wollmer, R. D. (1985). Critical path planning under uncertainty. In Mathematical Programming Essays in Honor of George B. Dantzig Part II(pp. 164-171). Springer Berlin Heidelberg.

Wu, S. D., Storer, R. H., \& Pei-Chann, C. (1993). One-machine rescheduling heuristics with efficiency and stability as criteria. Computers \& Operations Research, 20(1), 1-14.

Wu, S., Wan, H. D., Shukla, S. K., \& Li, B. (2011). Chaos-based improved immune algorithm (CBIIA) for resource-constrained project scheduling problems. Expert Systems with Applications, 38(4), $3387-3395$.

Wuliang, P., Min, H., \& Yongping, H. (2014). An improved ant algorithm for Multi-mode Resource Constrained Project Scheduling Problem. RAIRO-Operations Research, 48(4), 595-614.

Xiao, J., Wu, Z., \& Tang, J. C. (2014, July). Hybridization of electromagnetism with multi-objective evolutionary algorithms for RCPSP. In Proceedings of the 2014 Annual Conference on Genetic and Evolutionary Computation (pp. 653-660). ACM.

Xiao, J., Wu, Z., Hong, X. X., Tang, J. C., \& Tang, Y. (2016). Integration of electromagnetism with multi-objective evolutionary algorithms for RCPSP. European Journal of Operational Research, 251(1), 22-35.

Xiong, J., Chen, Y., Liu, J., \& Abbass, H. A. (2011, June). An evolutionary multi-objective scenariobased approach for stochastic resource investment project scheduling. In 2011 IEEE Congress of Evolutionary Computation (CEC) (pp. 2767-2774). IEEE.

Xiong, J., Liu, J., Chen, Y., \& Abbass, H. A. (2014). A knowledge-based evolutionary multiobjective approach for stochastic extended resource investment project scheduling problems. IEEE Transactions on Evolutionary Computation, 18(5), 742-763.

$\mathrm{Xu}, \mathrm{J} ., \quad \&$ Feng, C. (2014). Multimode resource-constrained multiple project scheduling problem under fuzzy random environment and its application to a large scale hydropower construction project. The Scientific World Journal, 2014.

Xu, J., Ma, Y., \& Xu, Z. (2015). A Bilevel Model for Project Scheduling in a Fuzzy Random Environment. IEEE Transactions on Systems, Man, and Cybernetics: Systems, 45(10), 1322-1335.

Yuan, X., Liu, J., \& Wimmers, M. O. (2015, May). A multi-agent genetic algorithm with variable neighborhood search for resource investment project scheduling problems. In 2015 IEEE Congress on Evolutionary Computation (CEC) (pp. 23-30). IEEE. 
Zadeh, L. A. (1965). Fuzzy sets. Information and control, 8(3), 338-353.

Zamani, R. (2013). An evolutionary search procedure for optimizing time-cost performance of projects under multiple renewable resource constraints. Computers \& Industrial Engineering, 66(2), 451460.

Zhang, H., Li, H., \& Tam, C. M. (2006). Particle swarm optimization for preemptive scheduling under break and resource-constraints. Journal of construction engineering and management, 132(3), 259267.

Zhang, Z. (2014, July). A MODM Bi-level Model with Fuzzy Random Coefficients for Resource-Constrained Project Scheduling Problems. In Computational Sciences and Optimization (CSO), 2014 Seventh International Joint Conference on (pp. 666-669). IEEE.

Zhenyuan, L., \& Hongwei, W. (2006). Heuristic algorithm for RCPSP with the objective of minimizing activities' cost. Journal of Systems Engineering and Electronics, 17(1), 96-102.

Zhu, J., Li, X., \& Shen, W. (2011). Effective genetic algorithm for resource-constrained project scheduling with limited preemptions. International Journal of Machine Learning and Cybernetics, 2(2), $55-65$.

Zhu, X., Ruiz, R., Li, S., \& Li, X. (2017). An effective heuristic for project scheduling with resource availability cost. European Journal of Operational Research, 257(3), 746-762.

Zoraghi, N., Shahsavar, A., Abbasi, B., \& Van Peteghem, V. (2017). Multi-mode resource-constrained project scheduling problem with material ordering under bonus-penalty policies. Top, 25(1), 49-79.

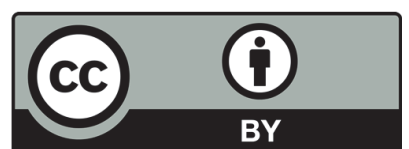

(C) 2018 by the authors; licensee Growing Science, Canada. This is an open access article distributed under the terms and conditions of the Creative Commons Attribution (CC-BY) license (http://creativecommons.org/licenses/by/4.0/). 